\title{
Advances in Computational Fluid Dynamics Applied to the Greenhouse Environment
}

\author{
Jorge Flores-Velázquez¹, Guillermo De la Torre-Gea², \\ Enrique Rico-García ${ }^{2}$, Irineo L. López-Cruz ${ }^{1}$ and Abraham Rojano-Aguilar ${ }^{1}$ \\ ${ }^{1}$ Department of Agricultural Engineering, University of Chapingo, Chapingo \\ ${ }^{2}$ Department of Biosystems, School of Engineering \\ Queretaro State University Querétaro \\ México
}

\section{Introduction}

In order to perform an accurate study of the climate inside a greenhouse, it is necessary to use models based on heat and mass transfer (Rico-García et al., 2008). Mathematical models based on mass and energy balances assume a homogeneous greenhouse environment. These models generate a set of nonlinear ordinary differential equations without an analytical solution. However, a more detailed monitoring of the environment inside the greenhouses reflects a two-dimensional and three-dimensional variability of climatic variables. Recently, this problem has been tackled using the fundamental equations of fluid dynamics. The set of numerical methods applied in order to solve those equations are called Computational Fluid Dynamics (CFD). Computational Fluid Dynamics (CFD) provides a numerical solution from an energy balance of a controlled volume, which in comparison with other methods and expensive technologies allows an efficient study of the climate inside the greenhouse. CFD techniques consider the values of the independent variables as primary unknowns in a finite number of places inside the domain, and then a set of algebraic equations are derived from the fundamental equations applied to the domain and can be solved by pre-establish algorithms.

In spite of, the greenhouse is a very complex bio-system, in which there are several physical, chemical and biological interacting process and phenomena, during the last decade, due to the development of computer simulation tools and the increase in computational processing power, it is possible to develop numerical models for the greenhouse environment such as more accurate models for transport phenomena and energy exchange inside the greenhouse. As a consequence, these studies have led improvements in the design of greenhouses (Norton et al., 2007).

According to Boulard et al. (2002), CFD is a branch of fluid mechanics that uses numerical methods and algorithms to solve and analyze problems involving fluids flow. Therefore, it is possible with the use of computers to perform millions of calculations to simulate the interaction of liquids and gases with surfaces defined by the boundary conditions. In recent studies the modeling of air flow, CFD has deepened to test their effectiveness in relationships of climatic factors (Bournet and Boulard, 2010). Computational parametric 
studies on greenhouse structures can help to the identification of design factors that affect greenhouse ventilation under specific climatic conditions (Romero-Gómez et al, 2008; Romero-Gómez et al., 2010).

In the last years, many studies have used CFD to investigate the climatic conditions inside greenhouses. CFD has been able to increase the degree of realism by taking into account insect-proof screens and simulation of the crop effect, considering it as a porous medium, among others in 3D models. The results have been able to improve our understanding of the phenomenon of greenhouse ventilation. Therefore, this chapter discusses significant recent studies to understand how the use of CFD has evolved.

\section{Fundamental CFD equations and methodology}

\subsection{Finite element models using CFD}

Computational fluid dynamics is based on the governing fluid dynamics equations (continuity, momentum and energy). The set of equations obtained directly from the volume or fixed element in space is known as "conservative form" Euler type. The equations obtained directly from the volume or movement with the fluid element are called "nonconservative form" Lagrange type (Anderson, 1995).

\subsection{Substantial derivative}

The substantial derivative physically is the exchange rate of any substance that moves with a fluid element. It consists of two parts, where the first part is called the local derivative, which means the rate of change over time in a fixed point. The second part is called the convective derivative, which physically is the exchange rate due to movement of the fluid from one point to another in the field of fluid, where the fluid properties are spatially different. The resulting material can be applied to any field variable fluid, for example: velocity $(u)$, pressure $(p)$ or temperature (T) (Anderson, 1995).

$$
\begin{gathered}
\nabla \equiv i \frac{\partial}{\partial x}+j \frac{\partial}{\partial y}+k \frac{\partial}{\partial z} \\
V \equiv(u, v, w) \\
\frac{\partial}{\partial t} \iiint_{V} \rho d V+\iint_{S} \rho V \cdot d S=0 \\
\rho \frac{D u}{D t}=-\frac{\partial p}{\partial x}+\frac{\partial t_{x x}}{\partial x}+\frac{\partial t_{y x}}{\partial x}+\frac{\partial t_{z x}}{\partial x}+\rho f_{x} \\
\rho \frac{D v}{D t}=-\frac{\partial p}{\partial x}+\frac{\partial t_{x y}}{\partial x}+\frac{\partial t_{y y}}{\partial x}+\frac{\partial t_{z y}}{\partial x}+\rho f_{y} \\
\rho \frac{D w}{D t}=-\frac{\partial p}{\partial x}+\frac{\partial t_{x z}}{\partial x}+\frac{\partial t_{y z}}{\partial x}+\frac{\partial t_{z z}}{\partial x}+\rho f_{z}
\end{gathered}
$$




$$
\begin{gathered}
\rho \frac{D w}{D t}\left(e+\frac{V^{2}}{2}\right)=\rho q+\frac{\partial}{\partial x}\left(k+\frac{\partial T}{\partial x}\right)+\frac{\partial}{\partial y}\left(k+\frac{\partial T}{\partial y}\right)+\frac{\partial}{\partial z}\left(k+\frac{\partial T}{\partial z}\right)-\frac{\partial(u p)}{\partial x}-\frac{\partial(v p)}{\partial y}-\frac{\partial(w p)}{\partial z} \\
+\frac{\partial\left(u t_{x x}\right)}{\partial x}+\frac{\partial\left(u t_{y x}\right)}{\partial y}+\frac{\partial\left(u t_{z x}\right)}{\partial z}+\frac{\partial\left(v t_{x y}\right)}{\partial x}+\frac{\partial\left(v t_{y y}\right)}{\partial y}+\frac{\partial\left(v t_{z y}\right)}{\partial z} \\
+\frac{\partial\left(w t_{x z}\right)}{\partial x}+\frac{\partial\left(w t_{y z}\right)}{\partial y}+\frac{\partial\left(w t_{z z}\right)}{\partial z}+p f \cdot V
\end{gathered}
$$

\section{Continuity equation}

2. Momentum equation (a non-conservative)

3. Components in $x, y$ and $z$

4. Energy equation (a non-conservative)

The fundamental CFD equations form a coupled system of nonlinear partial differential equations. So far no analytical solution has been found. It is commonly assumed that the fluid is an ideal gas where the intermolecular forces can be neglected. For an ideal gas, the state equation is:

$$
p=\rho R T
$$

Where $\mathrm{R}$ is the specific gas constant. For a calorically ideal gas we have:

$$
e=C v T \text {, }
$$

Where Cv is the specific heat at constant volume (Rodríguez, 2006, Norton et al, 2007).

\subsection{CFD procedure applied to the greenhouse environment}

Domain setting and grid generation are the first steps in the CFD modeling process. This implies the choice of a computational domain that is large enough to correctly assess the main mechanisms that occur in the system and to avoid interference with artificial Boundaries (Bournet and Boulard, 2010). The CFD modeling process encompasses three stages: preprocessing, solution and post-processing.

The preprocessing is the most time-consuming activity because of mesh generation that is the basis for an accurate simulation, does require heavy calculations. Therefore, keeping an adequate strategy should allow reliability in the calculations and physically consistent results. The meshing process is based on a serie of activities that can be summarized as follows:

a. Geometry definition (Figure 1)

b. Geometry decomposition

c. Computational mesh generation (Figure 2), refining, giggling, quality

d. Functional and quality meshing

e. Definition of the boundary conditions and

f. Export mesh

One of the most important problems currently in CFD modeling of the greenhouse environment is the time-consuming for a simulation to converge, due to the high number of cells that come from the process of meshing. Thus, for many years was chosen to model only 
in two dimensions (2D) (Flores-Velázquez, 2010). However, air distribution inner greenhouse has a third-dimensional (3D) pattern, for that, nowadays 3D CFD models are more commonly developed. According to Bournet and Boulard (2010) the calculation process is an iterative procedure that requires the definition of convergence criteria, and the user of the CFD codes must to decide on an appropriate level of convergence, of the solution. Generally, $10^{-4}$ of the value of a variable at all of the nodes is used. Faster convergence may also be reached by optimizing the grid shape or by assuming the Boussinesq model as density dependent rather than by setting up the problem on the basis of the ideal gas theory. However, this choice may not be applicable in the case of large thermal gradients and may also overlook the influence of temperature on air viscosity.
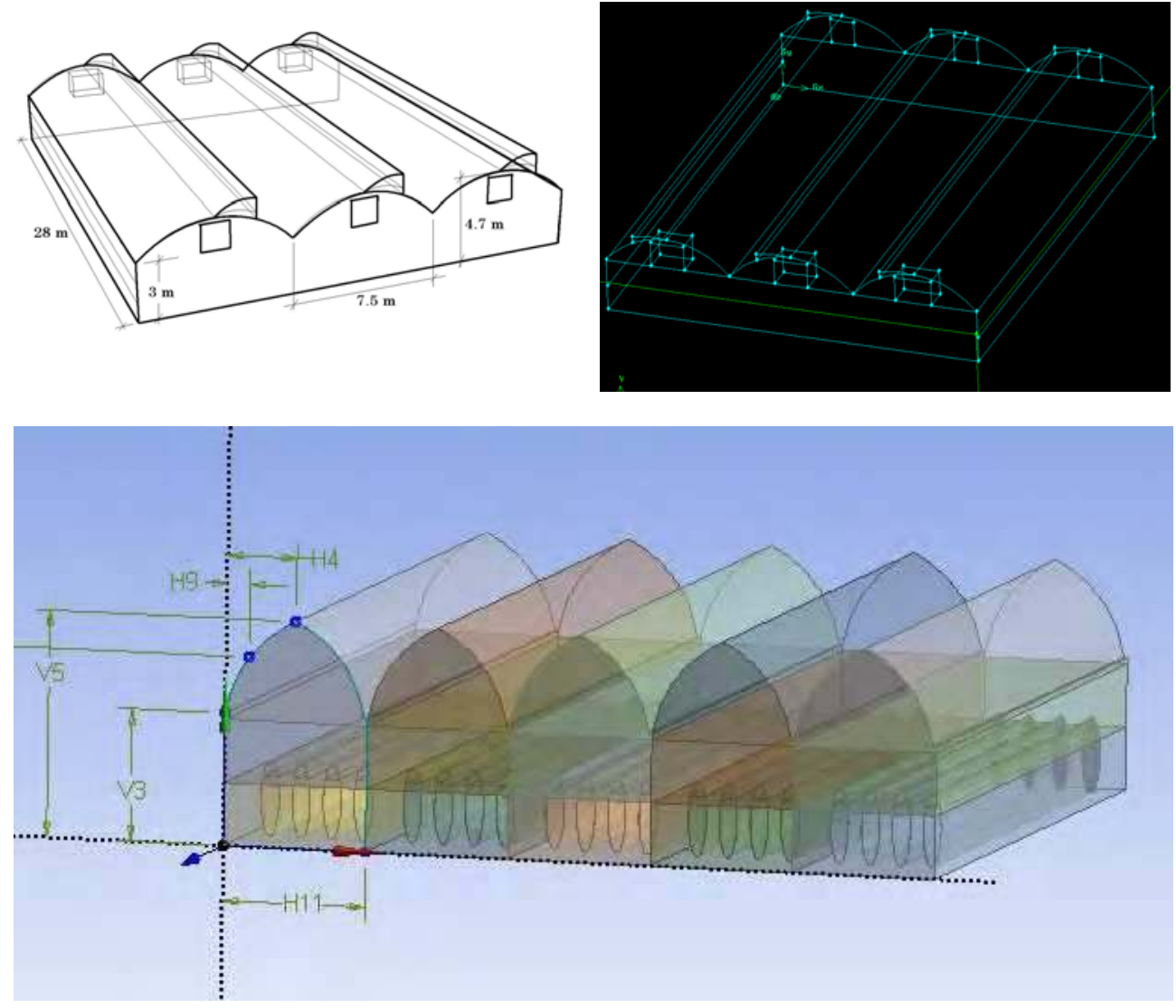

Fig. 1. Geometry generation for a greenhouse. 

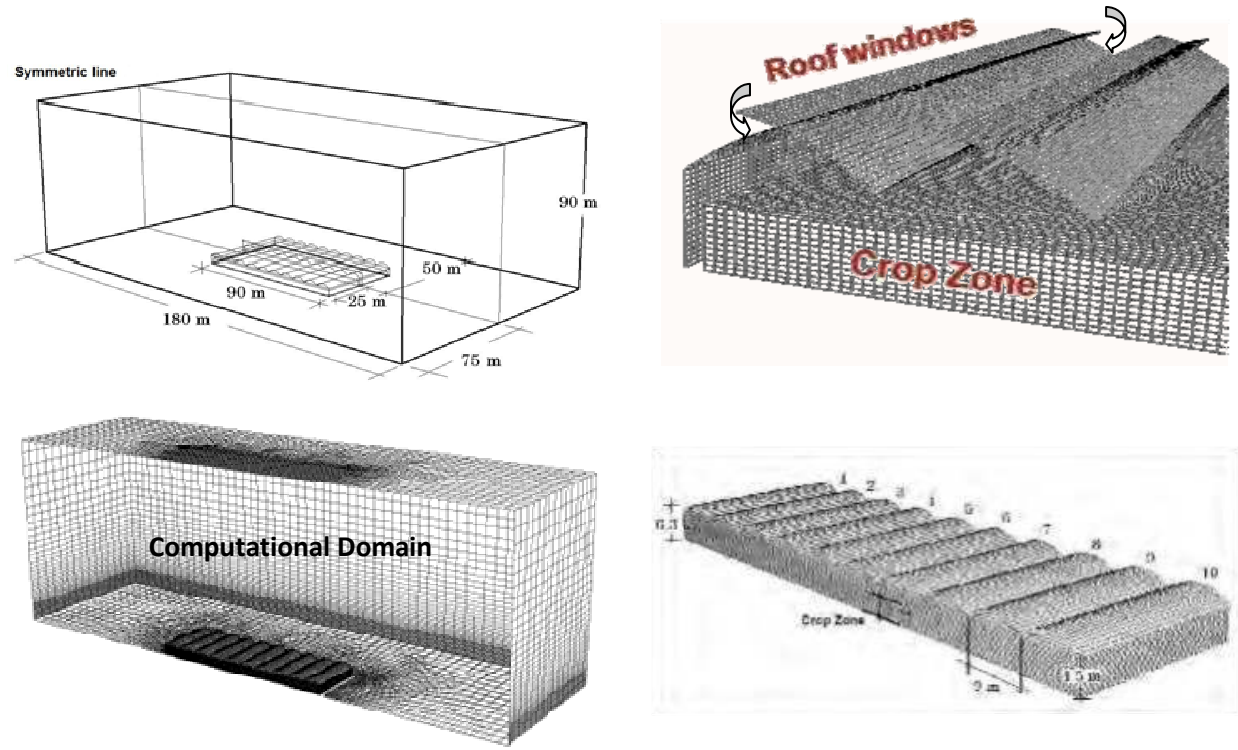

Fig. 2. Computational mesh generation for a greenhouse (Flores-Velázquez, 2010).

The presence of turbulence in a fluid is indicated by the fluctuating velocity components and the quantities carried out by the flow, even when the boundary conditions for the problem under study are kept constant. These fluctuations determine the difference between laminar flow and turbulent flow (Figure 3). For most situations, ventilation (effect of temperature, wind or both) measurements and visualization experiments have demonstrated the turbulent air flow inside and outside the greenhouse. Therefore, the phenomenon of turbulence must be taken into account (Norton et al. 2007).

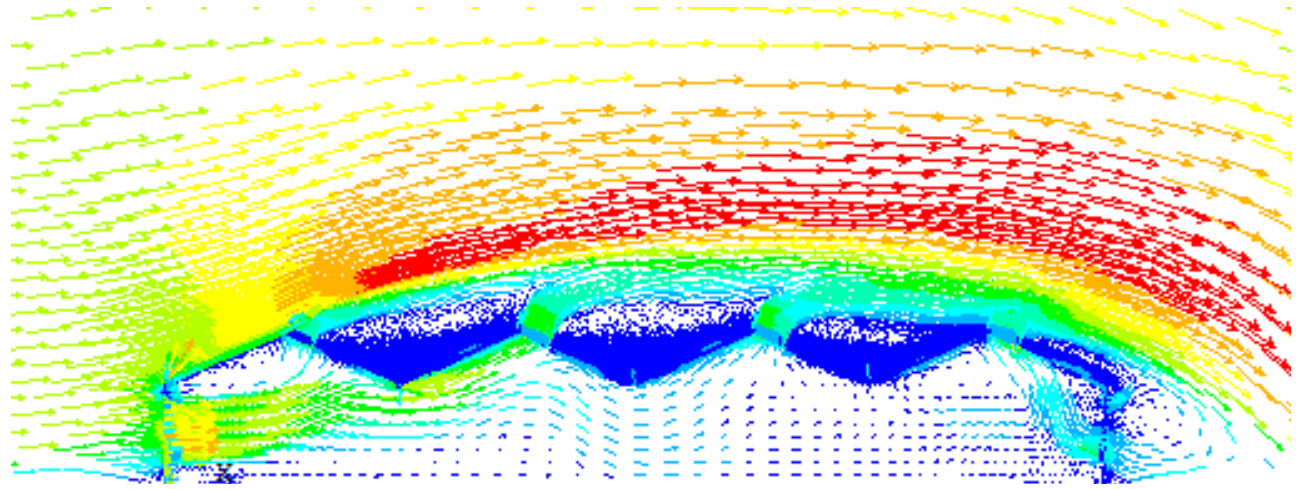

Fig. 3. Velocity vectors on a multi-hood greenhouse of four spans. CFD model considers anti-insect mesh vents (Rico-García, 2008). 
If inertial effects are large enough with respect to viscous effects, then the flow can be turbulent. Turbulence means that the instantaneous velocity varies at each point of the flow field. The turbulent nature of the velocity can be explained considering that the rate consists of the sum of two components, a main component (stable) and a fluctuating component. Depending on Reynolds number, laminar or turbulent flow can be modeled. For instance, most turbulence models, such as standard k- $\varepsilon$ Model, and Re-Normalized Group Turbulence Model (RNG), to name a few (Rico-García, 2008).

The post-processing stage allows the user to visualize and search for the solution. Figures contours, vectors and graphs can be obtained from analyzing the solution. It is remarkable that figures allow us to observe the full distribution of temperature, speed, pressure and so on the whole flow field (Figure 4).

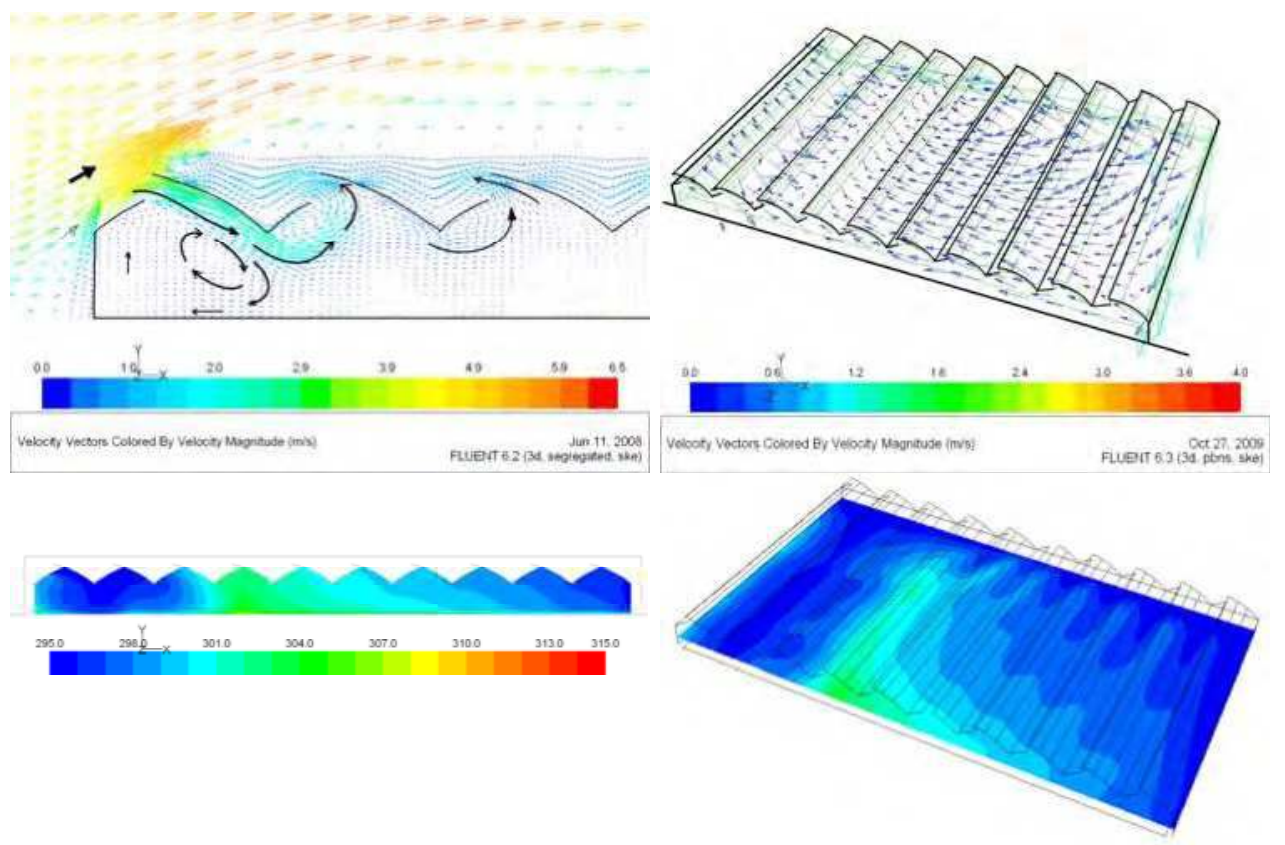

Fig. 4. Wind velocity $\left(\mathrm{m} \mathrm{s}^{-1}\right)$ and temperature $(\mathrm{K})$ representative post processing characteristics at different greenhouses sceneries (Flores-Velázquez, 2010)

As soon as a CDF model has been tested, the computational greenhouse environment can become a powerful climate analysis tool. Nowadays, it is possible to visualize, for instance, the wind distribution along the greenhouse when the income windows are up or down, and also the consequent temperature profiles, among many other possibilities (Figure 5). Even though, in the last decade research on wind behavior inside the greenhouse has been enormous, still, as a fundamental part of the greenhouse environment modeling process, it is necessary to take into consideration the physical verification in order to provide accuracy on the results obtained by numerical simulation (Flores-Velázquez, 2010). Scale models, water and wind tunnels and direct measurements of the climatic variables are some of the 
main options for verification of the CFD models of the greenhouse climate (FloresVelázquez, et al., 2011).

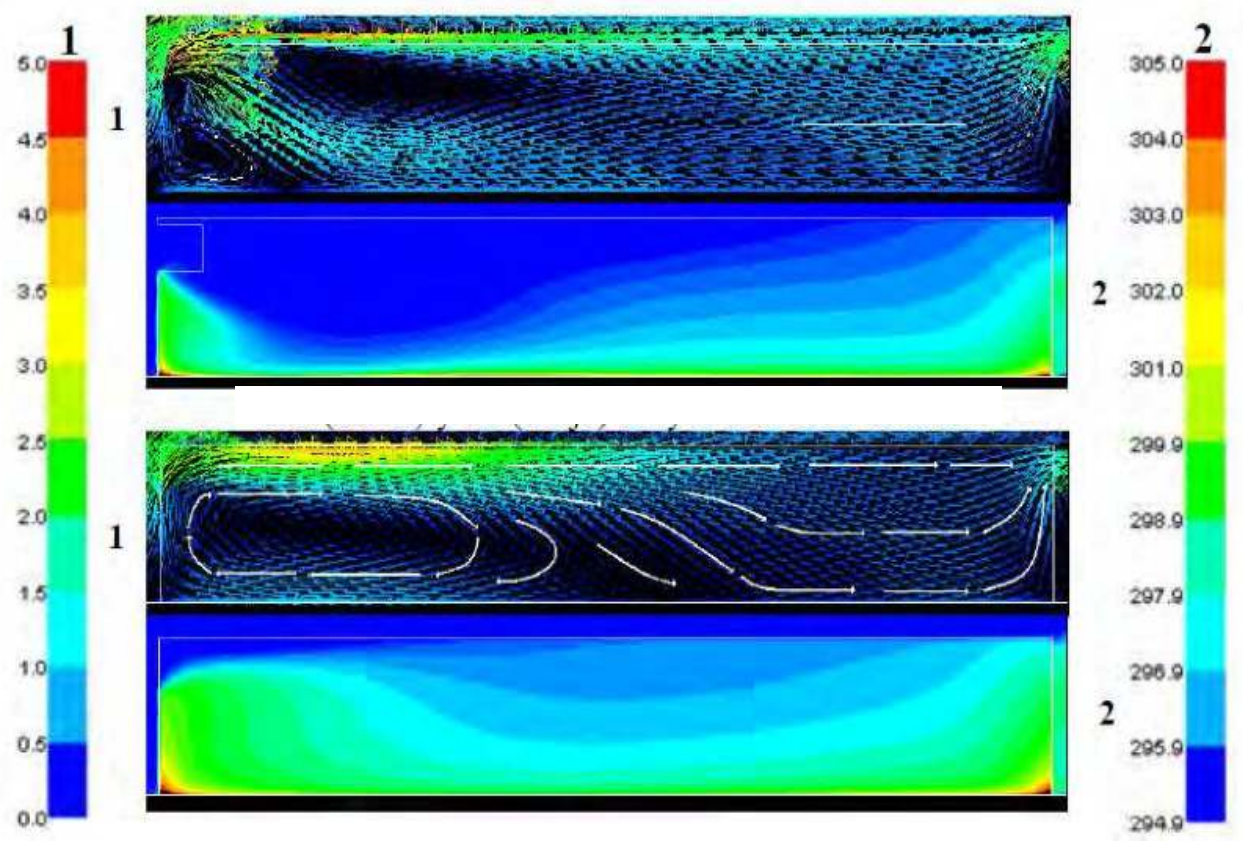

Fig. 5. Comparison of wind speed $\left(\mathrm{m} \mathrm{s}^{-1}\right)(1)$ and profiles of air temperature (K) (2) in the greenhouse with and without the projection of the rectangular window. Wind speed exterior $4 \mathrm{~m} \mathrm{~s}^{-1}$, soil heat flux $315 \mathrm{~W} \mathrm{~m}^{-2}$ (Flores-Velázquez, 2010).

\section{Approaches used in the application of CFD to the greenhouse environment}

CFD modeling is used to design facilities that provide suitable climatic conditions for the crops. According to Sase (2006), within a mild climate, appropriate design and control of ventilation are required to ensure effective cooling and uniformity of the environment. It is possible to design an optimal greenhouse by calculating its area, volume and vents area as well as the material properties of the roof (Impron et al., 2007). Rico-García et al. (2006), comparing two different greenhouses, showed the importance of its geometry and found that the ventilation rate for a greenhouse with larger vertical roof and windows was better than a multi-span greenhouse. Omer (2009) describes several designs of low energy greenhouses. In agreement with Baeza et al. (2008), design changes in the greenhouse, such as size and shape of vents, can improve air movement in the area of crops. Bakker et al. (2008) investigated energy balance, and determined that the amount of energy used per unit of output is defined by improvements in energy conversion, environmental control to reduce energy consumption and efficiency of agricultural production. In a study of outdoor 
areas using the turbulence model Reynolds-averaged Navier-Stokes equations (RANS), van Hoff (2010) found that small geometric modifications can increase the ventilation rate up to $43 \%$. The performance of ventilation in enclosed spaces is affected by the flow of outside air, type of cover, height of the installation and the ventilation opening (Kim et al., 2010). Computational parametric studies on greenhouse structures can help to identify design factors that affect greenhouse ventilation under specific climatic conditions (Romero-Gómez et al., 2008; Romero-Gómez et al., 2010; Flores-Velázquez et al., 2008).

\subsection{Windward and leeward wind directions}

The wind direction outside the greenhouse is an important factor in defining the flow of air and climate inside the greenhouse system. The boundary conditions of wind speed distribution are deduced from experimental data and wind direction with respect to the longitudinal axis of the greenhouse, which can range from $0^{\circ}$ to $90^{\circ}$. Roy and Boulard (2005) simulated the impact of wind at $45^{\circ}$ and $90^{\circ}$, showing the influence of wind direction in the air velocity, temperature and humidity distributions inside the greenhouse; a similar result was found by Campen (2003). Rico-García et al. (2006) also showed that a greenhouse with larger vertical roof windows works better with a windward condition, whereas the multi-span greenhouse works better with a leeward condition. Therefore, wind direction affects the degree of ventilation. In a experiment carried out by Khaoua et al. (2006), four different openings of roof vents obtained ventilation rates from 9 to 26.5 air exchanges per hour for the windward and 3.7 to 12.5 on the leeward wind condition, respectively, which can maintain acceptable and uniform climate conditions for particular cases where the wind is perpendicular to the main axis of the greenhouse. Overhead ventilation to the windward and leeward directions represents a reduction in the ventilation rate by $25 \%$ to $45 \%$, compared with only opening to the windward direction (Bournet et al., 2007). Openings to the windward direction generate the highest rate of ventilation; however, the greatest homogeneity of the temperature and wind speed arises from combining windward and leeward roof vents (Bournet and Khaoua, 2007).

Kacira et al. (2008) showed that the air temperature inside the greenhouse was higher on the windward side than on the leeward side when roof vents were used. Wind speed had a linear influence on air exchange rates, while the wind direction did not affect them. Majdoubi et al. (2009) observed a strong wind air current above a tomato canopy that was fed by a windward side vent and a slow air stream flowing within the tomato canopy space. The first third of the greenhouse, until the end of the leeward side, was characterized by a combination of wind and buoyancy forces, with warmer and more humid inside air that was removed through upper roof vents. There may be a conflict between increasing ventilation and improving uniformity because there is little information on air movement affecting the cooling efficiency and the uniformity of the environment (Sase, 2006). According to Rico-García (2008) the relationship between the thermal gradient and ventilation of gases shows a linear behavior, while the relationship between the combined effect of temperature and wind greenhouse ventilation presents a piecewise linear behavior. The wind pattern in a greenhouse is strongly affected not only by the outside wind velocity but also by the number of greenhouse spans (Flores-Velázquez, 2010). It was found recently, that as the greenhouse has three or four spans roof windows orientation is independent, however, when the greenhouse has five or more spans, side ventilation is dominant over the roof ventilation (Figure 6). 
By increasing the surface of the front windows, opening windows and increasing roof capacity exhaust fans can ventilate properly larger greenhouses (Figure 7). It is important to calibrate the fan power, but also to determine a representative inlet area (Flores-Velázquez et al., 2009; Flores-Velázquez, 2010).

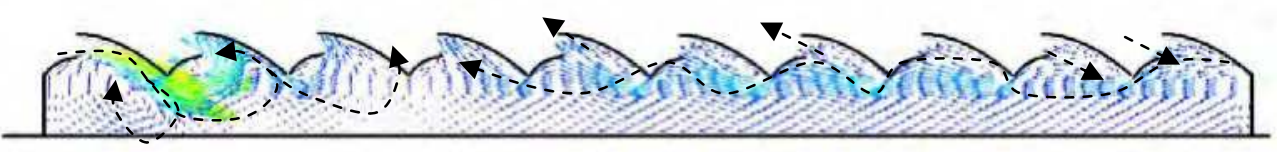

A) Roof windows windward open

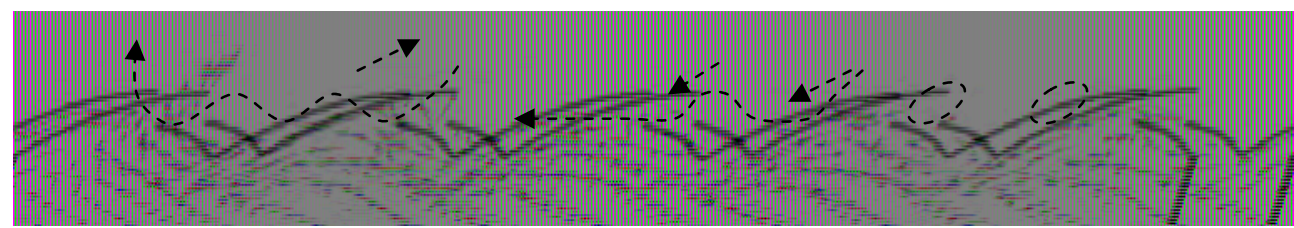

B) Roof windows leeward open

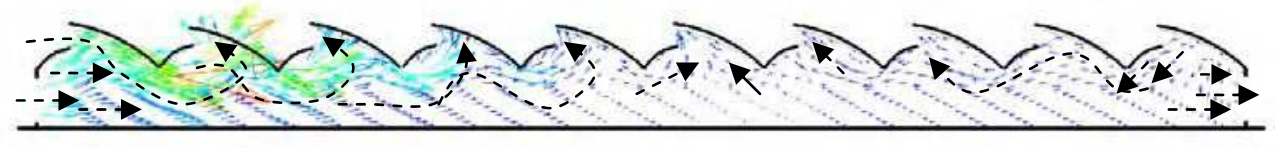

C) Roof and side windows windward open

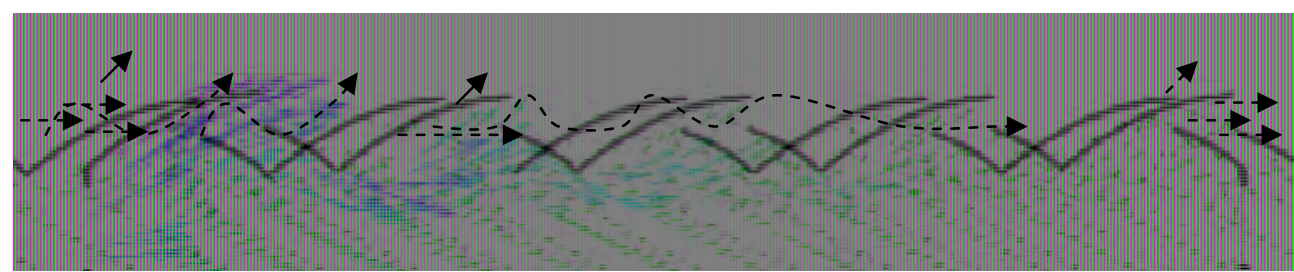

D) Roof and side windows leeward open

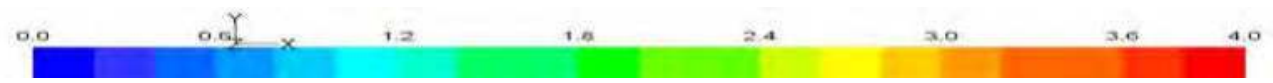

Fig. 6. Wind velocity interior vectors with $5 \mathrm{~m} \mathrm{~s}^{-1}$ wind velocity outside the greenhouse, on four open windows sceneries tested. 


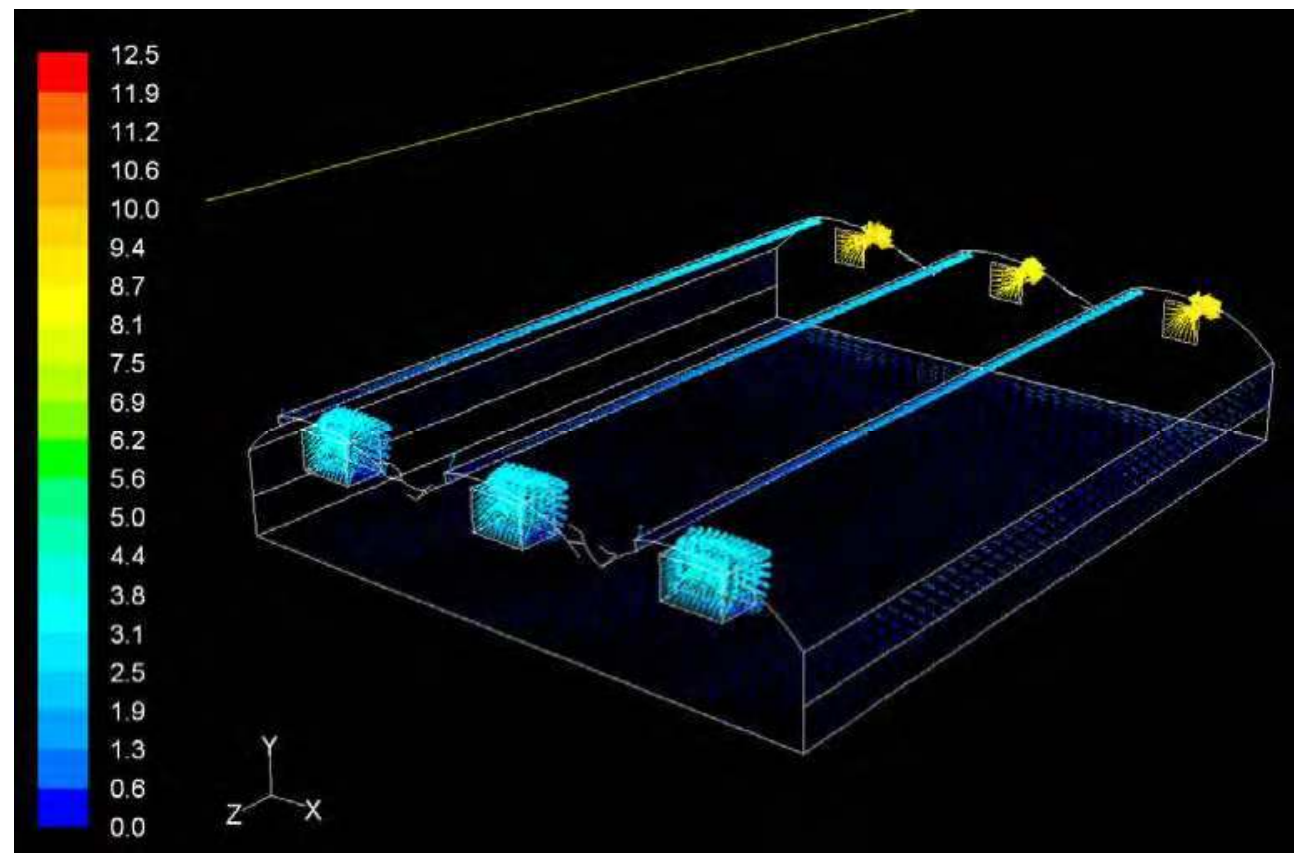

Fig. 7. Wind velocity vectors in a inlet area and outside fans in a three span greenhouse (Flores-Velazquez, 2010)

\subsection{Heat exchange tube and natural ventilation}

Rouboa and Monteiro (2007) simulated, by using a CFD model, the effects on temperature and wind speed of the introduction of hot water pipes along a greenhouse on nighttime conditions, under three scenarios: natural convection heating (case A), artificial heat pipes (case B) and artificial heat pipes and natural ventilation (case C) by using the turbulence model. Re-Normalization Group (RNG) observed an average increase in air temperature to $2.2^{\circ} \mathrm{C}, 6.7^{\circ} \mathrm{C}$ and $3.5^{\circ} \mathrm{C}$; the turbulence was lower for case A, slightly increasing with the heating system for case $B$ and higher for case $C$, due to the effect of natural ventilation.

\subsection{Forced ventilation}

The study of fluid dynamics in ventilation systems application provides elements of natural ventilation. A numerical investigation by Rousseau (2008) on a prototype air-forced unit for crop growth chambers obtained simulations that show a nonlinear relationship between airflow rate and opening vents, showing the mixing zone. Dayan et al. (2004) developed another simplified model to demonstrate the calculation of plant temperature when applying forced ventilation for climate control in greenhouses. The use of a device air flow deflector below the roof vents proved to increase air exchange in the area of cultivation effectively. According to the CFD simulations, the combination of the side vent dual configuration has little effect on overall air exchange; nonetheless it increases air movement in the crops and homogenizes temperatures (Baeza et al., 2008). Another investigation by Hughes and Abdul (2010) took into account the effect of the external angle of the ventilation 
device (wind vent) louvers against the internal pressure and velocity to optimize the device performance. The optimum angle was $35^{\circ}$ to $40^{\circ}$ with a wind velocity of $4.5 \mathrm{~ms}^{-1}$. Forced ventilation is an excellent option to abate the high temperature, but mainly in small greenhouses as fans are designed properly (Figure 8). As the length of the greenhouse increases, the overhead natural ventilation becomes a positive and more important complement to mechanical ventilation (Flores-Velazquez, 2010; Flores-Velázquez et al., 2011).
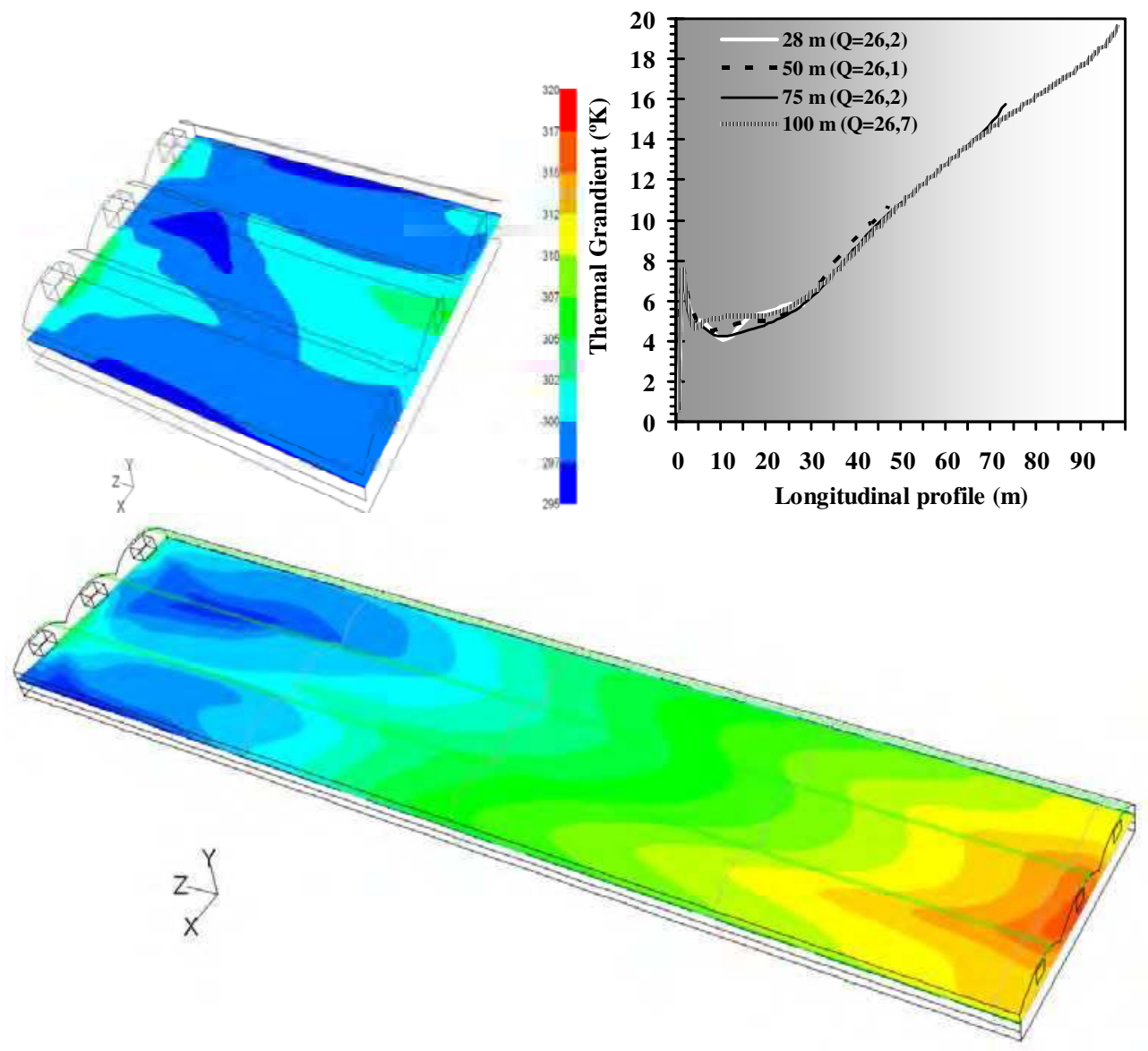

Fig. 8. Three spans mechanically ventilated greenhouse, power fan $25 \mathrm{~Pa}$, Heat flux convection $315 \mathrm{~W}$, top view $2 \mathrm{~m}$ high.

\subsection{Fog-cooling system}

According to Sase (2006), in a fog-cooled greenhouse in combination with natural ventilation, air cooled by fogging above the plants is likely to go down. Kim et al. (2007) developed a CFD model to simulate air temperature and relative humidity distribution in a greenhouse with 
fog-cooling systems, regardless of the presence of plants. Air temperatures and simulated measures ranged from $0.1^{\circ}$ to $1.4^{\circ} \mathrm{C}$ and relative humidity differences were $0.3-6.0 \%$. The results showed that the best cooling system performance occurs when fog nozzles are within 2.3 meters of the floor and $1.9 \mathrm{~m}$ of the side walls with a uniform spacing of $3.7 \mathrm{~m}$ and the best location for the injectors is at the entrance of the side openings of the greenhouse.

\subsection{Eave cladding type}

In order to understand the air mixing properties of the installation, Norton et al. (2010b) studied airflow and buoyancy, determining the relationship between eave openings and resistance to airflow and indoor air mixing for ventilation. They quantified the domain based on the effect of opening conditions, eave cladding type, porosity and height and found that the porosity of the eave opening cladding system significantly increases the efficiency of ventilation. They developed another CFD model incorporating shipping space and the cladding of the eave under conditions of opening and modifying its height, to determine the effects and characteristics of ventilation inside. It was found that the cladding of the eave influences the efficiency of ventilation and thermal comfort. They also found that the strength and the height of the eave determine whether it opens to leeward, acting as an air inlet (Norton et al., 2010c).

\subsection{Screens and vents}

Recent research using CFD models includes further refinement in adaptive meshing areas, in order to maintain a high level of accuracy during modeling making the simulations more reliable (Norton and Sun, 2006). Screens reduce ventilation rate by $33 \%$, according to a study carried out by Kittas et al. (2005). In agreement with Harmanto et al. (2006), using different screen's sizes over the vent opening has a significant effect, reducing $50 \%$ to $35 \%$ mesh 40 , 78 and 52 and giving rise to a temperature gradient of 1 to $3^{\circ} \mathrm{C}$ with a mesh of 52 as optimal for a tropical greenhouse. Majdoubi et al. (2007) found that insect-proof screens significantly reduced airflow, increasing thermal gradients inside the greenhouse by $46 \%$. Using a wind tunnel with screens of different porosity (0.62, 0.52 and 0.4$)$, Teitel et al. (2008a) showed that a screen inclined by airflow reduces drag compared to a flow perpendicular to the screen, allowing an increase of $15-30 \%$ and $25 \%$ in the upper compared with a flat screen. Also, Teitel et al. (2009) found that higher speed screens are inclined at $45^{\circ}$ and decreased to $135^{\circ}$ tilt.

Ali et al. (2009) investigated the effect of roof vents on the temperature and coefficient of heat transfer in naturally ventilated facilities. Better flow patterns and heat transfer from the heated ceiling are observed when the front opening is located closest to the ceiling and the rear opening is located closest to the center. The increase of temperature and humidity as a result of insect-proof screens is particularly evident in the vicinity of the crop canopy (Majdobi et al., 2009). Also it was found that a larger roof vent area can greatly enhance ventilation, while the extension of an insect-proof screen on side walls hardly changes the air exchange rate (Romero-Gómez et al, 2008; Romero-Gómez et al, 2010).

In hot regions a common practice is the substitution of the plastic cover of the greenhouse by a screen cover. This structure is called a screenhouse or a shadehouse. Although the climate control is rather difficult in such structure, it is an interesting and important system for growing crops. In some respect a screenhouse is better than a greenhouse as it is required to avoid hot air temperatures during specific hours of a day or a season, which is feasible because of the roof ventilation lets a higher air exchange (Figure 9). 


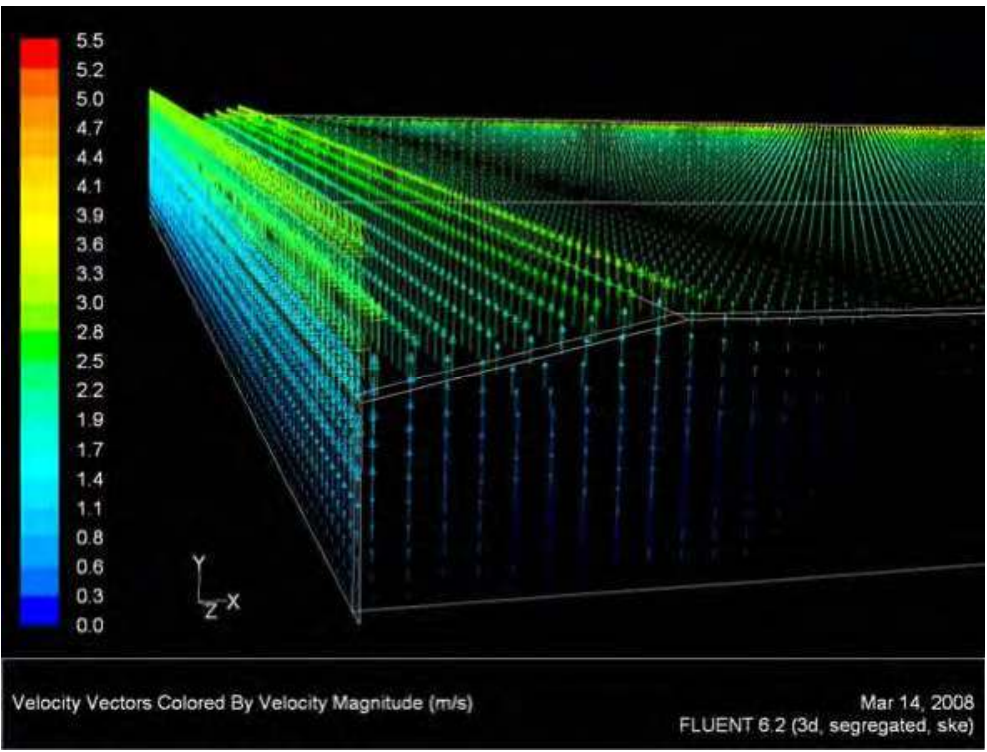

Fig. 9. Y-component wind velocities showing the wind exchange by the roof at entrance of a screenhouse (Flores-Velazquez, et al., 2008).

When several screen porosities are located on side/roof screenhouses a similar behavior is observed, regardless the kind of screen, and a strong reduction of the wind velocity is predicted as the crop effect is taken into account to simulate the CFD model of the screenhouse (Figure 10).

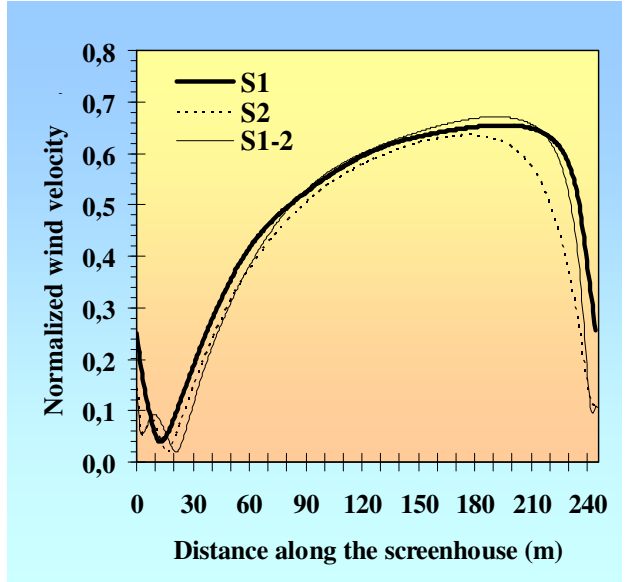

(a)

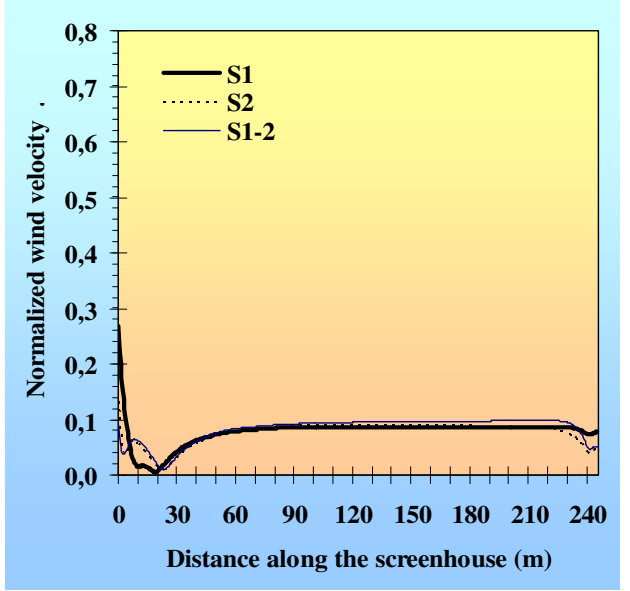

(b)

Fig. 10. Comparison of wind velocities between screenhouses with the same screen (S1 and S2) and screen on the side (S1) and screen on the roof (S2). (a) With crop effect simulated. (b) Without crop effect simulated. 


\subsection{Solar radiation and temperature}

Some studies have used solar radiation and transpiration models based on the heat and water balances of the crop, to investigate the distributions of air temperature and humidity and also the interactions between the crop and the air, in addition to the airflow distribution (Sase, 2006). According to Tablada (2005), the factor of solar protection plays a crucial role in maintaining stable thermal conditions indoors, even if the outside air temperature is higher. The slightly higher air speed on the top floor is insignificant in view of reducing the negative effect of the solar radiation over the roof and facade. The temperature of the greenhouse cover is an essential parameter needed for any analysis of energy transferred in the greenhouse. A sub-model developed by Impron et al. (2007) calculated the transmission of radiation through the greenhouse, including the reduction of NIR transmission through the roof. Tong et al. (2009) developed a numerical model to determine time-dependent temperature distributions based on hourly measured data for solar radiation, indoor air, soil and outside temperature, taking into account variable solar radiation and natural convection inside the greenhouse during the winter in northern China.

\subsection{Temperature and air exchange}

The effect of solar and thermal radiation is often taken into account by setting specific wall or heat fluxes at the physical boundaries of the greenhouse. Radiation transfer within the crop itself is still the major concern since it determines the two main physiological crop processes: transpiration and photosynthesis. This challenge is now launched and will probably receive more attention within the next few years (Bournet and Boulard, 2010). Pontikakos et al. (2006) analyzed data obtained from a CFD model, and showed that the external boundary temperature is a critical parameter in the pattern of internal greenhouse temperatures and that for specific external temperatures and wind directions, airspeed becomes the crucial parameter. According to Molina et al. (2006), opening vents affect the air flow, the ventilation rate and the air temperature distribution in a greenhouse; where the mean air temperature at the middle varied from 28.2 to $32.9^{\circ} \mathrm{C}$ with an outside air temperature of $26^{\circ} \mathrm{C}$, there were regions inside the greenhouse that were $13^{\circ} \mathrm{C}$ warmer than the outside air. Nebbali et al. (2006) used a semi-analytical method to determine the ground temperature profile from weather parameters and other characteristics, to help in evaluating heat flux exchange between the surface and the air. Rico-García et al. (2008) showed that ventilation in greenhouses due to the temperature effect produces high air exchange rates; however, those air patterns occur near the openings, causing almost no air exchange in the central zone of the greenhouse due to a stagnant effect that reduces the wind effect throughout the greenhouse. In agreement with the results of Majdoubi et al. (2009), convection and radiation are the dominant forms of heat transfer. The measurements show that the difference between the air temperature inside and outside the greenhouse is strongly linked to solar radiation and secondly to wind speed. However, Chow and Hold (2010) obtained the following conclusions from studying buoyancy forces from thermal gradients:

a. Thermal radiation without air involvement changes air temperature distribution by radiating upper zone thermal energy in the wall towards the lower zone wall, which then affects air temperature through conduction and convection;

b. The inclusion of air absorption increases the effect of radioactive thermal redistribution by allowing air to absorb and radiate heat, reducing temperature gradients further; 
c. Thermal boundary conditions and heat loads affect the predicted absolute temperature bounds, but do not affect the temperature distribution.

Radiation conditions play an important role in redistributing heat. Atmospheric conditions, especially relative humidity, are important for the calculation of radiation and heat transfer. Flores-Velázquez (2010) recently found that without overhead natural ventilation, it is possible to find linear relationships between temperature increase and the length of the greenhouse respectively, and the fan power that determines the slope of the regression line.

\subsection{Turbulence and buoyancy}

As computing power has increased the complexity and sophistication of CFD models also have increased. According to Norton and Sun (2006), the standard k- $\varepsilon$ turbulence model commonly used in CFD models for greenhouses, in some cases provides inadequate results, and the choice of turbulence models must be based on the phenomena involved in the simulation. Different turbulence models give rise to differences in speed, temperature and humidity patterns, confirming the importance of choosing the model that most closely matches the actual conditions of turbulence (Roy and Boulard, 2005). Teitel and Tanny (2005) showed that the output of the turbulent heat flux is mainly due to cold air entering the greenhouse, which produces hot and cold eddies coming in and out the greenhouse. Roy and Boulard (2005) showed that the effects of wind direction on climate parameters inside the greenhouse are usually simulated by using different turbulence models available, to determine the energy balance between the flow of perspiration and the flow of radiation. Under ventilation parameters based on Bernoulli's theorem, Majdoubi et al. (2007), showed that bad ventilation performance is not a result of the low value of the greenhouse wind-related ventilation efficiency coefficient, but rather, that the low rate of discharge due to pressure drop in air flow is generated both by the use of anti-insect screens with small openings as an obstruction due to the orientation of the rows of crops. Moreover, Rouboa and Monteiro (2007) note that the RNG turbulence model is best suited to simulate microclimates in arc-shaped greenhouses.

According to Baxevanou et al. (2007), the circulation of air buoyancy effect shows the importance of internal temperature gradients, forced convection resulting from natural ventilation predominates. Rico-García et al. (2008) found that applying temperatures as the main driven forces for the buoyancy effect provides a simple way to study ventilation and inner air patterns. Vera et al. (2010a) observed that differences in temperature and ventilation rates strongly influence the movement of air, pushing it through openings where space is colder, while creating rising air currents when it is hot. Majdoubi et al. (2009) showed that the buoyancy forces induced by air temperature and increased humidity result in loops of air between the crop and the roof windows, which in turn tend to accelerate the pace of removal of heat and water vapor, enhancing indoor climate. Fidaros et al. (2010) studied turbulence in Greek greenhouses and found that external temperature variation is very important because internal temperature is determined by convection induced by the input current. The housing area had a higher circulation in the center of the greenhouse near the deck and in the corners of the ground, where the effect of the input current is weak. Defraeye et al. (2010) used a RANS turbulence model in CFD simulations to evaluate heat transfer by forced convection at the surface of a cube immersed in a turbulent boundary layer for applications in the atmospheric boundary layer (ABL), where wind speed is not disturbed at a height of $10 \mathrm{~m}$. In a study of airfoil wakes, three turbulence models were simulated by Roberts and Cui (2010); the Reynolds Stress Model (RSM) is superior over the 
$\mathrm{k}-\varepsilon$ model, and when a time-dependent solution is necessary, Large Eddy Simulation (LES) is the desired option. However, LES does require the airfoil geometry to be included in the domain because it performs poorly when given only inlet velocities, turbulence kinetic energy and eddy dissipation at the trailing edge of the airfoil. According to Bournet and Boulard (2010), although they have been used for a long time in both the agriculture and environment studies, less empirical approaches to turbulence based on the use of LES have never been applied to greenhouse climate modeling and might perhaps be used to look for a solution to this complex situation.

Inside buildings, it is difficult to maintain a thermally stratified space with low ceilings, such as in offices and houses. Vera et al. (2010b) studied buoyancy in enclosed spaces, drawing the following conclusions:

a. Rising air currents and the exchange of humidity are closely related to the temperature difference between the lower and upper space. Low temperature in the upper space promotes the exchange of humidity and air flow through the opening; the hotter you are, the greater the restriction of air and humidity transport.

b. The existence of upward air currents when the space is warmer than the bottom is caused by local conditions such as non-uniform temperature distributions in the upper space and convective warm currents of the base and the humidity source.

c. Compared with conditions without mechanical ventilation, ventilation severely restricts the flow of air through the opening.

The main difficulty in the choice of the model is that greenhouse systems cover a range of length and velocity scales that generally require different modeling approaches (Bournet and Boulard (2010).

\subsection{Incorporation crop effects and crop modeling}

The effect of plants on greenhouse ventilation has also been studied in the past. For instance; Bournet et al. (2007), based on studies by Nederhoff (1985) and Lee and Short (1998), assumed that a crop of $90 \mathrm{~cm}$ high and low density decreases between 12 and 15\% greenhouse ventilation. Dayan et al. (2004) built a representative model of a greenhouse for three vertical segments, horizontally oriented to the directions of energy and vapor transfer between the segments containing plants, considering the external weather. They concluded that Representative Plant Temperatures (RPTs) can be calculated instead of measured. Roy and Boulard (2005) developed a 3D CFD model for the characterization of climatic conditions in a greenhouse, incorporating five rows of ripe tomatoes as a porous medium where the buoyancy, heat and moisture transfer between the crop and air flow inside were considered. The heat and moisture transfer coefficients are deduced from the characteristics of the laminar boundary layer of the leaf, which are calculated with the velocity of flow in the crop. Khaoua et al. (2006) found that under external conditions of $1 \mathrm{~ms}^{-1}$ air velocity and $30^{\circ}$ of temperature, wind speed at crops' height varies according to the modalities of ventilation from the windward 0.1 and $0.5 \mathrm{~ms}^{-1}$ for the leeward side, while temperature differences ranged from 2.0 to $6.1^{\circ} \mathrm{C}$. In a study with tomatoes, Majdoubi et al. (2007) found that crop rows oriented perpendicular to air movement reduce the rate of airflow through the cultivation in a greenhouse by $50 \%$. According to Baeza et al. (2008), a greenhouse with natural ventilation efficiency must combine an enough number of air changes to remove excess of heat, with good circulation of air through the crop. The effect of the crop was evaluated by Impron et al. (2007) using a sub-model to determine its effects on ventilation, the properties of the cover, and crop transpiration. In agreement with Kruger and Pretorius 
(2007), the temperature and velocity at the plant level are influenced by the arrangement and number of windows. A study carried out by Sapounas et al. (2007) simulated a tomato crop as a porous medium, taking into account the addition of buoyancy to develop a model of the pressure drop of air flow due to the crop. The model depended on the area leaf stage of growth and cultivation, under the RANS turbulence model together with the RNG k- $\varepsilon$ turbulence model. The results, validated with experimental measurements obtained at $1.2 \mathrm{~m}$ inside the canopy; show that the evaporative cooling system is effective with numerical parameters, providing a useful tool to improve system efficiency. A study performed by Roy et al. (2008) on leaf level through an experimental setup based on Münger cells measured the temperature, relative humidity and different heat flows to the leaves of soybeans, obtaining minimum stomatal resistance values ranging from 66 to $200 \mathrm{sm}^{-1}$.

Teitel et al. (2008b) built a small-scale model and found that wind direction significantly affects the ventilation rate and temperature distribution in crops. A study by von Elsner et al. (2008) on the effect of near-infrared (NIR) reflecting pigments in microclimate and plant growth found that a temperature drop up to $4^{\circ} \mathrm{C}$ in a young crop is the result of a $18 \%$ reduction in the transmission of global radiation in spring. At the same time, during the rainy season, minimizing transpiration differences in temperature and shading reduces water requirements in the plants, and they observed parthenocarpic fruit rot and yieldreducing crop. In a tunnel-type greenhouse, a tomato crop was modeled by Bartzanas et al. (2008) by designing a porous medium, where they emphasize the influence of the heating system on greenhouse microclimate. The climatic behavior of the rows of the tomato crop is taken into account using external user defined functions (Baxevanou et al., 2007). According to Majdoubi et al. (2009), reorienting crop rows in simple ways improved climatic conditions. Endalew et al. (2009) performed CFD modeling of a plant with leaves and branches of the canopy, using turbulent energy equations in porous sub-domains created around the branches. Fidaros et al. (2010) simulated a greenhouse tomato crop as a porous medium so as to model radiation transport by discrete ordinates (DO). According to Teitel et al. (2010a), when applying the porous medium approach, the Forchheimer equation is often used, which gives rise to erroneous results with respect to the pressure drop through screens. An alternative way to calculate it through several panels of porous media used to simulate screens with realistic geometries. Moreover, the crop exerts a mechanical strain (drag force) on the flow just above but also interacts through the transpiration process with the temperature and humidity distributions (Bournet and Boulard, 2010). A simple model of transpiration of a crop was developed by Sun et al. (2010), who related it to the characteristics of ventilation in a greenhouse in eastern China, obtaining a good approximation. In general, there have been enormous efforts devoted to the analysis of ventilation in greenhouses (Norton, 2007); each new study provides new elements not only in the movement of air in the greenhouse but also in the forms it takes due to interactions occurring in the environment, such as position, shape and size of windows, and (one of the most important), the presence of a crop (Flores-Velázquez, 2010).

\subsection{Humidity}

Roy and Boulard (2005) simulated wind directions of $0^{\circ}, 45^{\circ}$ and $90^{\circ}$ with respect to the orientation of the greenhouse ridge to determine wind speed, temperature and humidity distributions inside the greenhouse, getting a good approximation for the humidity. In agreement with Demrati et al. (2007), models allow estimation, with better accuracy, of water requirements for a banana crop under cover and improved water saving in regions 
where water is the main limiting factor for agriculture. Roy et al. (2008) studied moisture on the surface of leaves at low light levels; crop transpiration and air flow were integrated into a single parameter model of leaf stomatal response to air flow and radiation. Campen (2008) showed that climate through a ventilation system is more homogeneous and the control is more efficient than with the conventional method of steam extraction. Dehumidifiers and cooling reduce the overall difference in humidity between the middle and lower areas of a greenhouse, as demonstrated by Kim (2008) using a 3D model could identify the heterogeneous distribution of relative humidity in a greenhouse. According to Majdobi et al. (2009), an increase in air temperature precedes a more moderate increase in specific humidity.

\section{Main results of CFD models in greenhouses}

Many CFD studies are focused on defining the conditions for a suitable environment. There has been less work on automation and control variables. Investigations that seek for a greater understanding of the interactions among climatic variables are increasing. Studies such as those of Hooff, 2010; Teittel, 2010 and Fidaros, 2010, evaluating geometries, have increased in the last year. Figure 11 shows the frequency of climatic variables studied during the period from the year 2005 to 2009 in the studies of CFD models in greenhouses.

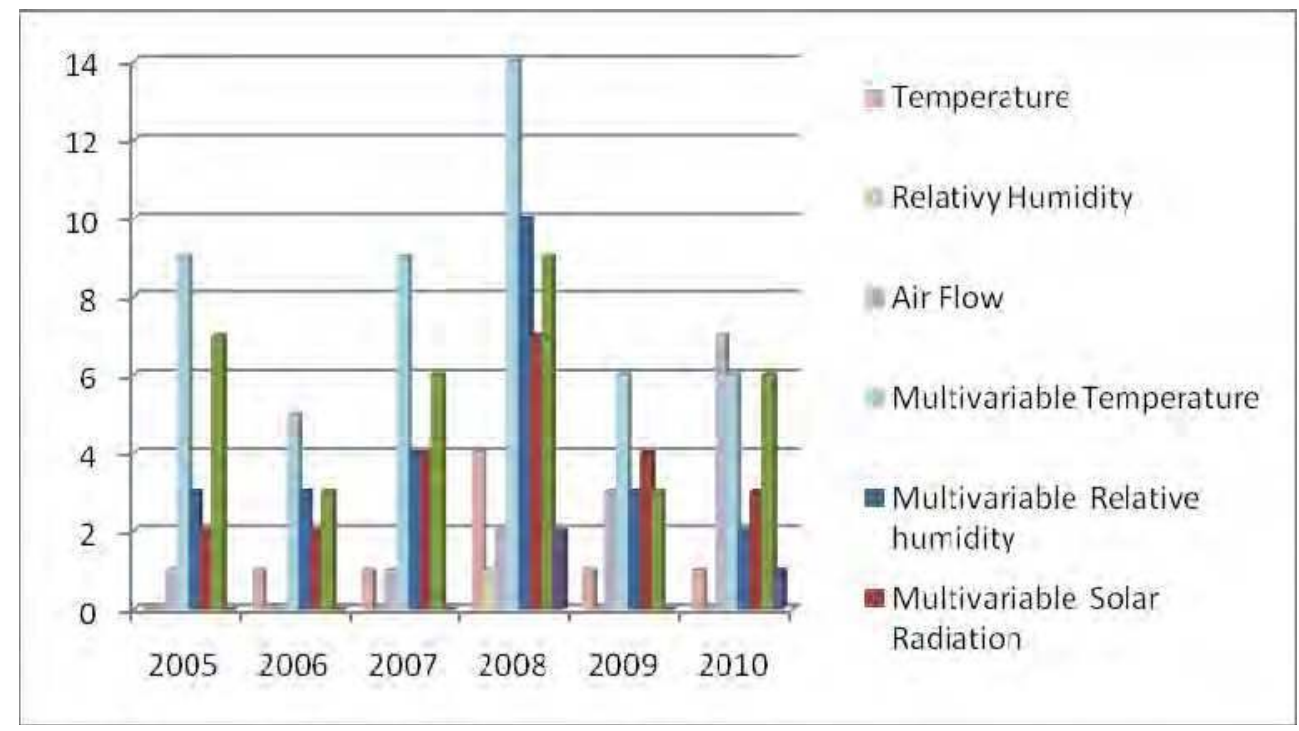

Fig. 11. Frequency of climatic variables analyzed by CFD models applied to greenhoses.

Most studies show multi-variable relationships, of which temperature and air flow are predominant. Humidity has been linked to temperature, while there are still few $\mathrm{CO}_{2}$ distribution models. Solar radiation is the subject of investigations that evaluate housing, and is also related to the temperature in simulations with a greater degree of realism.

Studies to determine the influence of windward and leeward wind direction indicate that roof vents are of great importance for air renewal, where aperture settings that maximize the 
number of air renewals are obtained only with windows open to the windward roof (Bournet et al., 2007; Kacira, 2008 and Majdoui, 2009). However, the combination of openings to the windward and leeward sides homogenizes the temperature inside the greenhouse better (Bournet and Khaoua, 2007). There have been many studies to determine a kind of optimal geometric design of greenhouses that encourage improvements in weather conditions and the use of new technologies such as monitoring systems in real time, allowing improvements in automation using Web technology (Pontikakos, 2005). Other studies have focused on the evaluation of misting systems (Kim et al., 2007; Gázquez et al. 2008), forced ventilation (Dayan et al., 2004, Baeza et al., 2008 and Hughes and Abdul 2010) looking for energy savings. As simulation technology and computing power have improved, accuracy and realism in research based on CFD models, has increased as well, by defining more detailed models and by the use of textures that define the materials of the facilities.

The use of insect-proof screens in commercial greenhouses is very important as a means of crop protection; even though they reduce natural ventilation, by this, there have been many research efforts to reduce its negative influence (Kittas et al., 2005; Harmanto et al., 2006; Majdoubi et al., 2007; Teitel et al., 2008a). These studies tested different designs in size of the box and tilt and determined the most affected areas within the greenhouse, where the use of porous media allowed its CFD simulation.

Several studies have investigated the influence of solar radiation on temperature and relative humidity (Tablada et al., 2005; Impron et al., 2007, Tong et al., 2009), and the result in crop response (Baxevanou et al., 2007). Other studies evaluated the use of pigments (Elsner et al., 2008) taking into account the convection, and thermal gradients.

Most of the recent studies developed 3D CFD models, some of which reported the use of models of turbulence and buoyancy, which appear more often during the past two years (Fidaros, 2010; Defraeye, 2010; Norton, 2010; Majdoubi, 2009). By taking into account turbulence, CDF models can make simulations more accurate, in turn increasing the processing and memory requirements for computing resources. Norton and Sun (2006) and Roy and Boulard (2005) discuss the importance of choosing the turbulence model that best meets the conditions of the study. Moreover, the concept of buoyancy appears frequently in order to incorporate the effects of growing space on the air flow and temperature gradients into the models (Figure 12).

Many studies consider the growing space, some of which are designed to measure phenomena based on their influence on the development and crop yield. Other studies are focused on the influence of crops on the other elements, such as temperature, relative humidity, $\mathrm{CO}_{2}$ concentration and air flow, where it is necessary to model the space occupied by the crop by using porous media approach (Fidaros et al ., 2010). Other investigations measure biological phenomena such as evapotranspiration and Photosynthetically Active solar Radiation (PAR) by using indirect measures of climatic variables (Baxevanou, 2007; Sun, 2008). However, some studies do not mention an experimental phase aimed at validating the numerical model. In studies of air flow, the experimental methods mostly used are scaled models and unidirectional anemometry; the tracer gas technique is used less often, as well as three-dimensional anemometry, which is considerably more expensive. Studies that have used new methods to assess ventilation systems, such as those by Lu (2009), Molina (2010), Endalew (2009), van Henten (2008), Mikulka (2010) and Defraeye (2010), have been increasing in the past three years. The main question is the validation of these studies because they mainly concern to real scale greenhouses, whereas the measurements and characterizations have merely been done on scale models. 


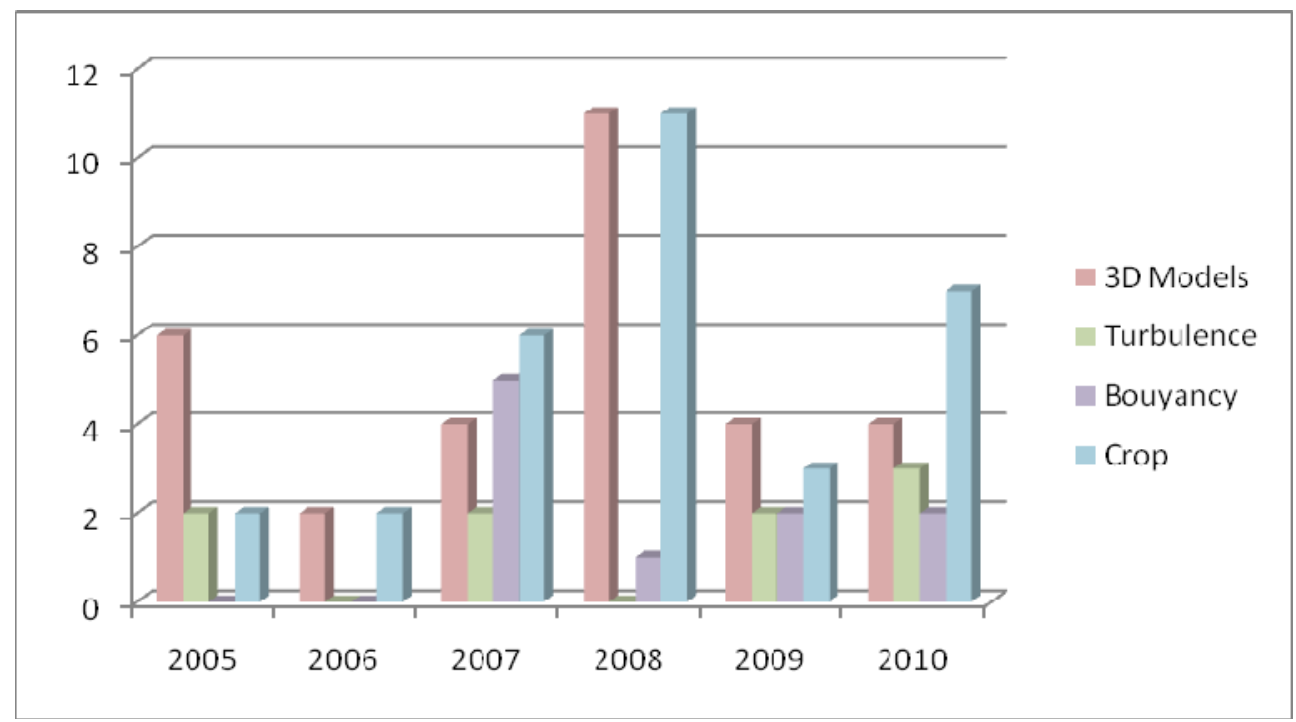

Fig. 12. Degree of realism and accuracy in the CFD models for greenhouse climate.

CFD modeling is an area of knowledge that in recent years has developed enormously through the development of software and hardware, which has contributed to research on natural ventilation a greater understanding of the interactions between the variables that make up the climate inside greenhouses. In the past five years, CFD simulation has become increasingly realistic and detailed, obtaining more accurate solutions. However, their use requires depth and extensive knowledge of climatic variables, fluid dynamics and turbulence. Simulating more accurately requires more processing power, so research tends to use CFD models together with other tools. Further studies are required to incorporate more realistic crops beyond a porous medium, taking into account the role of gas exchange, which is necessary for an understanding of the physiology and phenology of crops. There is still a need to develop high-precision systems in greenhouses, and CFD is a powerful tool for defining parameters with high precision, in order to control better the greenhouse environment.

\section{Validation procedures for CFD models of greenhouse environment}

\subsection{Models and experimental validation}

According to Sase (2006), recent progresses in CFD techniques have accelerated a more detailed analysis of air movement in combination with verification tests. However, studies in this area are required in order to address the detailed design of each element involved in the greenhouse climate, highlighting the difficulty involved in the analysis of air movement inside a greenhouse (Flores-Velázquez, 2010). The quality of the CFD models predictions is often evaluated from the agreement with experimental data. Nevertheless, no standard procedure exists yet in order to properly assess the accuracy of the simulations, and the type of comparison often differs from one study to the next (Bournet and Boulard, 2010). Figure 13 summarizes the main approaches used in the recent past to validate the CFD models of the greenhouse environment. 


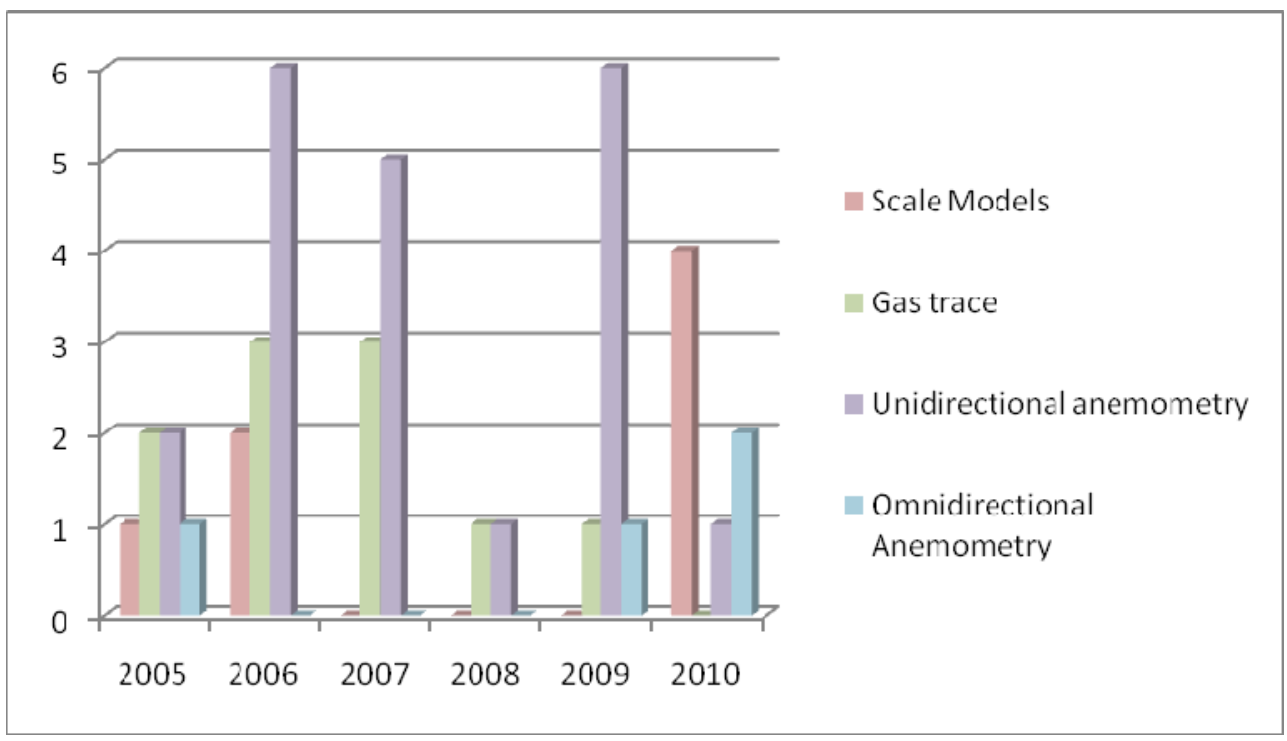

Fig. 13. Frequency of validation procedures used in CFD models applied to greenhouses.

The use of porous media models to simulate the pressure drop across flow boundaries, such as insect screens and fences, is very popular and must be validated experimentally. New technologies such as particle image velocimetry have worked properly to complement predictions; field solutions may include biological responses increasing the realism of the simulations (Norton et al., 2007). According to Rouboa and Monteiro (2007), improvements could be achieved by incorporating nighttime transpiration and optimizing the size of the mesh elements to lower computation time. Recent progress offers the opportunity to build a grid that fits the physical boundaries of the structures studied much more realistically than a Cartesian structured grid, which closely follow the contour of the solid boundaries. However, they require verification of the meshing quality to obtain accurate data and an appropriate computational convergence (Bournet and Boulard, 2010).

\subsection{Statistical models}

The statistical models developed by Pontikakos et al. (2006) are less computationally expensive than the original CFD model, and therefore, they could be used for real-time estimates of temperature and flow rate in a greenhouse.

\subsection{Model types}

In a small-scale model developed by Teitel et al. (2008b), wind direction significantly affected the ventilation rate and temperature distribution in crops. Chen et al. (2010) evaluated seven types of models (analytical, empirical, experimental small-scale, pilot-scale, multi-area network and CFD to predict the ventilation rate in crops, obtaining the following conclusions:

a. The analysis of the model can give an overall assessment of a ventilation system if flow can be approximated to obtain a solution. 
b. The empirical model has similar abilities to the model of analysis, but develops a database.

c. The small-scale model can be useful to examine the complex problems of ventilation if a similarity of flow can be maintained between the model and reality.

d. The large-scale model is the most reliable in predicting the efficiency of ventilation, but is expensive and time consuming.

e. The multi-zone model is a useful tool for the design of the ventilation of an entire building, but cannot provide detailed flow information in a room.

f. The zone model can be useful when a user has prior knowledge of the flow in a room.

g. The CFD model provides more detailed information on the performance of ventilation and is the most sophisticated.

However, the model must be validated by corresponding experimental data and the user must have depth knowledge of fluid mechanics and numerical technique. Therefore, the choice of an appropriate model depends on the problem to be solved.

\subsection{Finite Element vs. Finite Volume}

In a study by Molina et al. (2010), on the effectiveness of the Finite Element Method (FEM) and Finite Volume Method (FVM) for two-dimensional incompressible turbulent flow in ventilation rates, it was found that the FEM requires twice the computation time and 10 times more memory storage than FVM. FVM software (ANSYS/FLUENT v 6.3.) is the most frequently used CFD package in ventilation research, and only few papers using FEM software (ANSYS/FLOTRAN v. 11.0) have been published. CFD simulations have been compared to experimental data for 12 cases corresponding to three greenhouse types. The experimental greenhouses were chosen to represent a large range of ventilation situations: buoyancy effect in a mono-span greenhouse with adiabatic walls, as well as buoyancy and wind effect in a multi-span greenhouse and ventilation.

\section{Looking into the future}

Advances in telecommunications such as wireless networking and Internet technology (TCP / IP) facilitate the monitoring of environmental conditions in greenhouses. Pontikakos et al. (2005) designed a Web-based application for real-time predictive modeling of temperature and air velocity patterns, which consists of a user interface, interpolation process data generated by CFD and an output interface.

A lighting systems model with different optical properties was developed by Mikulka et al. (2010) who shows various settings for the R-FEM method in the CFX environment.

CFD ventilation space still tends to be a slow process today, while the computation time for the ventilation system and control simulation strategy is negligible. Sun and Wang (2010) found that the test method is more effective than the simplified numerical models, which require more powerful computers. Stavrakakis et al. (2010) concluded that Artificial Neural Networks coupled with CFD models are a powerful computational tool to evaluate the energy savings of various architectural designs.

Currently, CFD studies that mainly considered natural ventilation, increasing the realism of simulations by adding features such as the modeling of the crop inside greenhouse. However, it is still necessary to model crop physiological processes such as respiration and transpiration that define the terms of $\mathrm{CO}_{2}$ and relative humidity mainly in crop space (De la Torre-Gea and Rico-García, 2010). 


\section{References}

Ali, A.A.A.; Nabil, M.G. \& Mahmoud, A.H (2009). Effect of natural ventilation and wind direction on the thermal performance of a building ceiling, Proceedings Of ISES World Congress 2007, Vol. I-V, Springer, No. 2, pp. 436-440.

Anderson, J.D. (1995). Computational Fluid Dynamics. ISBN: 978-3-540-85055-7, McGrawHill, US.

Baeza, E.J.; Perez-Parra, J.J.; Lopez, J.C. \& Montero, J.I. (2008). CFD simulation of natural ventilation of a parral greenhouse with a baffle device below the greenhouse vents. Acta Horticulturae, No. 801, pp. 885-892.

Bakker, J.C.; Adams, S.R.; Boulard, T. \& Montero, J.I. (2008). Innovative technologies for an efficient use of energy. Acta Horticulturae, No. 801, pp. 49-62.

Bartzanas, T.; Tadj, N.; Draoui, B. \& Kittas, C. (2008). Numerical and experimental analysis of convective heat transfer in a heated greenhouse. Acta Horticulturae, No. 801, pp. 847-854.

Baxevanou, C.; Bartzanas, T.; Fidaros, D. \& Kittas, C. (2008). Solar radiation distribution in a tunnel greenhouse. Acta Horticulturae, No. 801, pp. 855-862.

Bournet, P.E.; Ould Khaoua, S.A.; Boulard, T.; Migeon, C. \& Chassériaux, G. (2007). Effect of roof and side opening combinations on the ventilation of a greenhouse using computer simulation. American Society of Agricultural and Biological Engineers, No. 50, pp. 201-212.

Bournet, P.E. \& Ould Khaoua, S.A. (2007). Predicted effects of roof vent combinations on the climate distribution in a glasshouse considering radioactive and convective heat transfers. Acta Horticulturae, No. 801, pp. 925-932.

Bournet, P.E. \& Boulard, T. (2010). Effect of ventilator configuration on the distributed climate of greenhouses: A review of experimental and CFD studies. Computers and Electronics in Agriculture, No. 74, pp. 195-217.

Campen, J.B. (2008). Vapor removal from the greenhouse using forced ventilation when applying a thermal screen. Acta Horticulturae, No. 801, pp. 863-868.

Chen, Q. (2009). Ventilation performance prediction for buildings: a method overview and recent applications. Building and Environment, No. 44, pp. 848-858.

Chen, Q; Lee, K.; Mazumdar, S.; Poussou, S.; Wang, L.; Wang, M. \& Zhang, Z. (2010). Ventilation performance prediction for buildings: model assessment. Building and Environment, No. 45, pp. 295-303.

Chow, K.; \& Hold, A.E. (2010). On the influence of boundary conditions and thermal radiation on predictive accuracy in numerical simulations of indoor ventilation. Building and Environment, No 45, pp. 437-444.

Dayan, J.; Dayan, E.; Strassberg, Y. \& Presnov, E. (2004). Simulation and control of ventilation rates in greenhouses. Mathematics and Computers in Simulation, No. 65, pp. 3-17.

Defraeye, T.; Blocken, B. \& Carmeliet, J. (2010). CFD analysis of convective heat transfer at the surfaces of a cube immersed in a turbulent boundary layer. Int. J. Heat Mass Tran., pp.297-308.

De la Torre-Gea, G. \& Ríco-García, E. (2010). Crop Under Greenhouse Simulations as Porous Media in Computational Fluid Dynamics Models. Proceedings of The 5th symposium of engineering, Queretaro State University, Queretaro, Mexico, November 2010. 
Endalew, A.M.; Hertog, M.; Gebrehiwot, M.G.; Baelmans, M.; Ramon, H.; Nicolaï, B.M. \& Verboven, P. (2009). Modelling airflow within model plant canopies using an integrated approach. Computers and Electronics in Agriculture, No. 66, pp. 9-24.

Fidaros, D.K.; Baxevanou, C.A.; Bartzanas, T. \& Kittas, C. (2010). Numerical simulation of thermal behavior of a ventilated arc greenhouse during a solar day. Renewable Energy, No. 35, pp. 1380-1386.

Flores-Velázquez, J. (2010). Climate analysis in the main models of greenhouses in Mexico (mesh shade and Baticenital multitunnel) using CFD. PhD Tesis, Almeria University, Spain.

Flores-Velázquez, J. \& Montero J.I. (2008). Computational fluid dynamics CFD study of large-scale screenhouse. Acta Horticulturae, No. 797, pp. 117-122.

Flores-Velázquez, J.; Montero, J.I; Baeza, E.J.; Lopez, J.C.; Bonachela, S. \& Pérez-Parra, J.J. (2009). Analysis of mechanical ventilation in a three span greenhouse using computational fluid dynamics (CFD). Acta Horticulturae No. 893, pp. 653-660.

Flores-Velázquez, J.; Mejía, E.; Montero, J.I.; \& Rojano, A. (2011). Numerical analysis of the inner climate in a mechanically-ventilated greenhouse with three spans. Acepted in Agrociencia.

Gan, G. (2009). CFD modelling of transparent bubble cavity envelopes for energy efficient greenhouses. Building and Environment, No. 44, pp. 2486-2500.

Gan, G. (2010). Impact of computational domain on the prediction of buoyancy-driven ventilation cooling. Building and Environment, No. 45, pp. 1173-1183.

Hughes, B.R. \& Ghani, S.A.A. (2010). A numerical investigation into the effect of windvent louvre external angle on passive stack ventilation performance. Building and Environment, No. 45, pp. 1025-1036.

Iglesias, N.; Montero, J.I.; Muñoz, P. \& Antón, A. (2009). Study for the night weather and the use of double cover roof as a passive alternative to increase temperature in greenhouses through a model based in computational fluid dynamics (CFD). Horticultura Argentina, No. 28, pp. 18-23.

Impron, I.; Hemming, S. \& Botb, G.P.A. (2007). Simple greenhouse climate model as a design tool for greenhouses in tropical lowland. Biosystems Engineering, No. 98, pp. 79-89.

Kacira, M.; Sase, S.; Ikeguchi, A.; Ishii, M.; Giacomelli, G. \& Sabeh, N. (2008). Effect of vent configuration and wind speed on three-dimensional temperature distributions in a naturally ventilated multi-span greenhouse by wind tunnel experiments. Acta Horticulturae, No. 801, pp. 393-401.

Khaoua, S.A.O.; Bournet, P.E.; Migeon, C.; Boulard, T. \& Chassériaux, G. (2006). Analysis of greenhouse ventilation efficiency based on computational fluid dynamics. Biosystems Engineering, No. 95, pp. 83-98.

Katsoulas, N.; Bartzanas, T.; Mermier, M. \& Kittas, C. (2006). Effect of vents opening and insect screen on greenhouse ventilation. Biosystems Engineering., No. 94, pp. 427436.

Kim, K.; Giacomelii, G.A.; Yoon, J.Y.; Sase, S.; Son, J.E.; Nam, S.W. \& Lee, I.B. (2007). CFD modeling to improve the design of a fog system for cooling greenhouses. Japan Agricultural Research Quarterly, No. 41, pp. 283-290.

Kim, K.; Yoona, J.Y.; Kwonb, H.J.; Hana, J.H.; Sonc, J.E.; Namd, S.W.; Giacomelli, G.A. \& Lee, I.B. (2008). 3-d cfd analysis of relative humidity distribution in greenhouse 
with a fog cooling system and refrigerative dehumidifiers. Biosystems Engineering, No. 100, pp. 245-255.

Kim, T.; Kim, K. \& Kim, B.S. (2010). A wind tunnel experiment and cfd analysis on airflow performance of enclosed-arcade markets in korea. Building And Environment, No. 45, pp. 1329-1338.

Kruger, S. \& Pretorius, L. (2007). The effect of ventilator configurations in naturally ventilated greenhouse applications. Proceedings of $10^{\text {th }}$ Uk Heat Transfer National Conference, Edinburgh, Scotland, September, pp. 10-11.

Majdoubi, H.; Boulard, T.; Hanafi, A.; Bekkaoui, A.; Fatnassi, H.; Demrati, H.; Nya, M. \& Bouirden, L. (2007). Natural ventilation performance of a large greenhouse equipped with insect screens. American Society of Agricultural and Biological Engineers, No. 50, pp. 641-650.

Majdoubi, H.; Boulard, T.; Fatnassi, H. \& Bouirden, L. (2009). Airflow and microclimate patterns in a one-hectare canary type greenhouse: an experimental and CFD assisted study. Agricultural and Forest Meteorology, No. 149, pp. 1050-1062.

Mercado-Luna, A.; Rico-García, E.; Lara-Herrera, A.; Soto-Zarazúa, G.; Ocampo-Velázquez, R.; Guevara-González, R.; Herrera-Ruiz, G. \& Torres-Pacheco, I. (2010). Nitrogen determination on tomato (Lycopersicon esculentum Mill.) seedlings by color image analysis (RGB). African Journal of Biotechnology, No. 9, Vol. 33, pp. 5326-5332.

Mikulka, J; Kriz, T.; Kroutilova, E. \& Fiala, P. (2010). Numerical modeling of light sources with R-Fem method in CFX environment. Piers Proceedings, March 22-26, pp. 424-427.

Molina-Aiz, F.D.; Valera, D.L.; Pena, A.A.; Alvarez, A.J. \& Gil, J.A. (2006). Analysis of the effect of rollup vent arrangement and wind speed on Almería-type greenhouse ventilation performance using Computational Fluid Dynamics. Acta Horticulturae, No. 719, pp. 173-180.

Molina, F.D.; Fatnassi, H.; Boulard, T.; Roy, J.C. \& Valera, D.L. (2010). Comparison of finite element and finite volume methods for simulation of natural ventilation in greenhouses. Computers and Electronics in Agriculture, No. 72, pp. 69-86.

Nebbali, R.; Makhlouf, S.; Boulard, T. \& Roy, J.C. (2006). A dynamic model for the determination of thermal boundary conditions in the ground of a greenhouse. Acta Horticulturae, No. 719, pp. 295-302.

Norton, T. \& Sun, D.W. (2006). Computational Fluid Dynamics (CFD) an effective and efficient design and analysis tool for the food industry: a review. Trends in Food Science \& Technology, No. 17, pp. 600-620.

Norton, T.; Sun, D.W.; Grant, J.; Fallon, R. \& Dodd, V. (2007). Applications of Computational Fluid Dynamics (CFD) in the modeling and design of ventilation systems in the agricultural industry: a review. Bioresource Technology, No. 98, pp. 2386-2414.

Norton, T.; Grant, J.; Fallon, R. \& Sun, D.W. (2009). Assessing the ventilation effectiveness of naturally ventilated livestock buildings under wind dominated conditions using Computational Fluid Dynamics. Biosystems Engineering, No. 103, pp. 78-99.

Norton, T.; Grant, J.; Fallon, R. \&, Sun, D.W. (2010a). Optimising the ventilation configuration of naturally ventilated livestock buildings for improved indoor environmental homogeneity. Building And Environment, No. 45, pp. 983-995.

Norton, T.; Grant, J.; Fallon, R. \& Sun, D.W. (2010b). Assessing the ventilation performance of a naturally ventilated livestock building with different eave opening conditions. 
Computers and Electronics in Agriculture, No. 71, pp. 7-21.Norton, T.; Grant, J.; Fallon, R. \& Sun, D.W. (2010c). A Computational Fluid Dynamics study of air mixing in a naturally ventilated livestock building with different porous eave opening conditions. Biosystems Engineering, No. 106, pp. 125-137.Norton, T.; Grant, J.; Fallon, R. \& Sun, D.W. (2010d). Improving the representation of thermal boundary conditions of livestock during CFD modeling of the indoor environment. Computers and Electronics in Agriculture, article in press.

Omer, A.M. (2009) Constructions, applications and the environment of greenhouses. African Journal of Biotechnology, No. 8, Vol. 25, pp. 7205-7227.

Pontikakos, C.; Ferentinos, K.P. \& Tsiligiridis, T.A. (2005). Web-based estimation model of natural ventilation efficiency in greenhouses using 3D Computational Fluid Dynamics. In Proceedings of the International Congress on Information Technologies in Agriculture, Food and Environment, October: 12-14.

Pontikakos, C.; Ferentinos, K.P.; Tsiligiridis, T.A. \& Sideridis, A.B. (2006). Natural ventilation efficiency in a twin-span greenhouse using 3D Computational Fluid Dynamics. Of The 3rd International Conference on Information and Communication Technologies in Agriculture, September: 20-23.

Rico-García, E.; Reyes-Araiza, J.L. \& Herrera-Ruiz, G. (2006). Simulations of the climate in two different greenhouses. Acta Horticulturae, No. 719, pp. 325-332.

Rico-García, E.; López-Cruz, I.L.; Herrera-Ruiz, G.; Soto-Zarazua, G.M. \& CastanedaMiranda, R. (2008). Effect of temperature on greenhouse natural ventilation under hot conditions: Computational Fluid Dynamics simulations. Journal of Applied Sciences, No. 8, pp. 4543-4551.

Rico-García, E. (2008). Climate Modeling Greenhouse: Natural Ventilation. PhD Tesis, Queretaro State University, México.

Roberts, R.A. \& Cui, J. (2010). Selection of the simulation domain of turbulent flow around and airfoil. Engineering Aplications of Computational Fluid Mechanics, No. 4, pp. 441-449.

Rodríguez, N.Y. (2006). Fundamental Equations of Fluid Dynamics. Universidad de la Habana, Facultad de Matemática y Computación, Ciudad de la Habana, Cuba.

Romero-Gómez, P.; Choi, C.Y. \& Lopez-Cruz, I.L. (2010). Enhancement of the greenhouse air ventilation rate under climate conditions of central Mexico. Agrociencia No. 44, pp. 1-15.

Romero-Gómez, P.; López-Cruz, I.L. \& Choi, C.Y. (2008). Analysis of greenhouse natural ventilation under the environmental conditions of central México. Transactions of the $A S A B E$, Vol. 51(5), pp. 1753-1761.

Rousseau, T. (2008). Structure design and indirect adaptive general predictive temperature control of a class of passive HVAC. WSEAS Transactions On Systems and Control, No. 3, pp. 493-502.

Rouboa, A. \& Monteiro, E. (2007). Computational Fluid Dynamics analysis of greenhouse microclimates by heated underground tubes. Journal of Mechanical Science and Technology, No. 21, Vol 12, pp. 2196-2204.

Roy, J.C. \& Boulard, T. (2005). CFD prediction of the natural ventilation in a tunnel-type greenhouse: influence of wind direction and sensibility to turbulence models. Acta Horticulturae, No. 691, pp. 457-464. 
Roy, J.C.; Vidal, C.; Fargues, J. \& Boulard, T. (2008). CFD based determination of temperature and humidity at leaf surface. Computers and Electronics in Agriculture, No. 61, pp. 201-212.

Sapounas, A.A.; Nikita-Martzopoulou, C.; Bartzanas, T. \& Kittas, C. (2007). Aspects of CFD modeling of fan and pad evaporative cooling system in a greenhouses. International Journal of Ventilation. No. 6, pp. 379-388.

Sase, S. (2006). Air movement and climate uniformity in ventilated greenhouses. Acta Horticulturae, No. 719, pp. 313-324.

Seo, I.H.; Lee, I.B.; Moon, O.K.; Kim, H.T.; Hwang, H.S.; Hong, S.W.; Bitog, J.P.; Yoo, J.I.; Kwon, K.S.; Kim, Y.H. \& Han, J.W. (2009). Improvement of the ventilation system of a naturally ventilated broiler house in the cold season using computational simulations. Biosystems Engineering, No. 104, pp. 106-117.

Stavrakakis, G.M.; Zervas, P.L.; Sarimveis, H. \& Markatos, N.C. (2010). Development of a computational tool to quantify architectural-design effects on thermal comfort in naturally ventilated rural houses. Building and Environment, No. 45, pp. 65-80.

Sun, H.; Yang, J. \& Wang, X. (2010). CFD based determination of crop transpiration in local greenhouses in eastern china. On 4th International Conference, Bioinformatics and Biomedical Engineering, pp. 1-4.

Sun, Z. \& Wang, S. (2010). A CFD-based test method for control of indoor environment and space ventilation. Building and Environment, No. 45, pp. 1441-1447.

Tablada, A.; Blocken, B.; Carmeliet, J.; De Troyer, F. \& Verschure, H. (2005).The influence of courtyard geometry on air flow and thermal comfort: CFD and thermal comfort simulations. Proceedings of 22nd Conference on Passive and Low Energy Architecture, No.1, pp. 75-80.

Teittel, M.; \& Tanny, J. (2005). Heat fluxes and airflow patterns through roof windows in a naturally ventilated enclosure. Flow, Turbulence and Combustion, No. 74, Vol. 1, pp.: 21-47.

Teitel, M.; Liron, O; Haim, Y. \& Seginer, I. (2008a). Flow through inclined and concertinashape screens. Acta Horticulturae, No. 801, pp. 99-106.

Teittel, M.; Ziskind, G.; Liran, O.; Dubovsky, V. \& Letan, R. (2008b). Effect of wind direction on greenhouse ventilation rate, airflow patterns and temperature distributions. Biosystems Engineering, No. 101, pp. 351-369.

Teitel, M.; Dvorkin, D.; Haim, Y.; Tanny, J. \& Seginer, I. (2009). Comparison of measured and simulated flow through screens: effects of screen inclination and porosity. Biosystems Engineering, No. 104, pp. 404-416.

Teittel, M. (2010). Using Computational Fluid Dynamics Simulations to determine pressure drops on woven screens. Biosystems Engineering, No. 105, pp. 172-179.

Tong, G.; Christopher, D.M. \& Li, B. (2009). Numerical modelling of temperature variations in a chinese solar greenhouse. Computers and Electronics in Agriculture, No. 68, pp. 129-139.

Van Hoff, T. \& Blocken, B. (2010). Coupled urban wind flow and indoor natural ventilation modelling on a high-resolution grid: a case study for the amsterdam arena stadium. Environmental Modelling \& Software, No. 25, pp. $51-65$. 
Vera, S.; Fazio, P. \& Rao, J. (2010a). Interzonal air and moisture transport through large horizontal openings in a full-scale two-story test-hut: part 2 - CFD study. Building and Environment No. 45, pp. 622-631.

Vera, S.; Fazio, P. \& Rao, J. (2010b). Interzonal air and moisture transport through large horizontal openings in a full-scale two-story test-hut: part 1 - experimental study. Building and Environment, No. 45, pp. 1192-1201. 


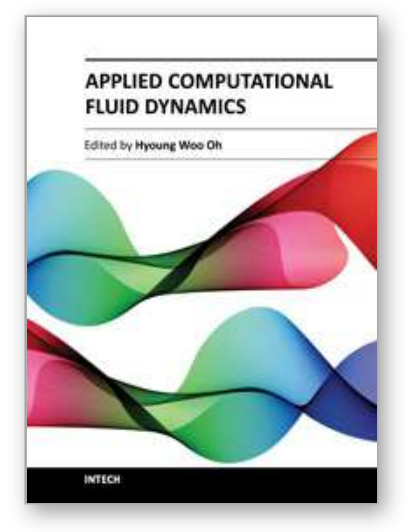

\section{Applied Computational Fluid Dynamics \\ Edited by Prof. Hyoung Woo Oh}

ISBN 978-953-51-0271-7

Hard cover, 344 pages

Publisher InTech

Published online 14, March, 2012

Published in print edition March, 2012

This book is served as a reference text to meet the needs of advanced scientists and research engineers who seek for their own computational fluid dynamics (CFD) skills to solve a variety of fluid flow problems. Key Features: - Flow Modeling in Sedimentation Tank, - Greenhouse Environment, - Hypersonic Aerodynamics, Cooling Systems Design, - Photochemical Reaction Engineering, - Atmospheric Reentry Problem, - FluidStructure Interaction (FSI), - Atomization, - Hydraulic Component Design, - Air Conditioning System, Industrial Applications of CFD

\section{How to reference}

In order to correctly reference this scholarly work, feel free to copy and paste the following:

Jorge Flores-Velázquez, Guillermo De la Torre-Gea, Enrique Rico-García, Irineo L. López-Cruz and Abraham Rojano-Aguilar (2012). Advances in Computational Fluid Dynamics Applied to the Greenhouse Environment, Applied Computational Fluid Dynamics, Prof. Hyoung Woo Oh (Ed.), ISBN: 978-953-51-0271-7, InTech, Available from: http://www.intechopen.com/books/applied-computational-fluid-dynamics/advances-incomputational-fluid-dynamics-applied-to-the-greenhouse-environment

\section{INTECH}

open science | open minds

\section{InTech Europe}

University Campus STeP Ri

Slavka Krautzeka 83/A

51000 Rijeka, Croatia

Phone: +385 (51) 770447

Fax: +385 (51) 686166

www.intechopen.com

\section{InTech China}

Unit 405, Office Block, Hotel Equatorial Shanghai

No.65, Yan An Road (West), Shanghai, 200040, China

中国上海市延安西路65号上海国际贵都大饭店办公楼 405 单元

Phone: +86-21-62489820

Fax: $+86-21-62489821$ 
(C) 2012 The Author(s). Licensee IntechOpen. This is an open access article distributed under the terms of the Creative Commons Attribution 3.0 License, which permits unrestricted use, distribution, and reproduction in any medium, provided the original work is properly cited. 